\title{
Grain Prices, Oil Prices, and Multiple Smooth Breaks in a VAR
}

\author{
Walter Enders \\ Department of Economics, Finance \& Legal Studies \\ University of Alabama \\ Tuscaloosa, AL 35487 \\ wenders@culverhouse.ua.edu \\ Paul Jones \\ Social Science Division \\ Seaver College \\ Pepperdine University \\ Malibu, CA 92063 \\ paul.jones@pepperdine.edu
}

October 2014

\begin{abstract}
Ignored structural breaks in a VAR result in a misspecified model such that Granger causality tests are improperly sized; there is a bias towards a rejection of the null hypothesis of non-causality even when the null is correct. Instead of modeling structural breaks as being sharp, changes in the relationship between the maize and petroleum markets are likely to have occurred gradually. We show the Flexible Fourier Form has good size and power properties in testing for smooth structural change in a VAR. When applied to a VAR including maize and oil prices, we uncover important linkages between the two markets.
\end{abstract}

Key Words: Flexible Fourier Form, Nonlinear VAR, Smooth Structural Breaks 


\section{Introduction}

There is no question that the world markets for petroleum and grains have been subjected to a number of large shocks. In the 1970s, there were two major rounds of oil price increases along with a run-up of grain prices resulting from crop failures in Europe and U.S. grain sales to the Soviet Union. More recently, the linkages between grain and petroleum prices have changed in a number of important ways as a result of the growth of the BRIC (Brazil, Russia, India, and China) countries and because of legislation requiring increasing amounts of biofuels in gasoline. The Energy Policy Act of 2005 created a new link between the price of oil and the price of biofuels that is projected to grow over time. Biofuels, typically bioethanol, can be produced from maize (corn), sugarcane, or sorghum. ${ }^{1}$ As reported in Table 1, the growth in the worldwide production of biofuels has been exceptional.

Table 1: Growth Rates of Biofuel Production (thousands of barrels per day) ${ }^{2}$

$\begin{array}{ccccccccccc}2001 & 2002 & 2003 & 2004 & 2005 & 2006 & 2007 & 2008 & 2009 & 2010 & 2011 \\ 9.0 \% & 17.7 \% & 23.8 \% & 11.1 \% & 18.3 \% & 28.1 \% & 31.3 \% & 33.9 \% & 10.7 \% & 14.1 \% & 1.7 \%\end{array}$

The United States now operates under a renewable fuel standard such that ethanol production is subsidized and ethanol imports are restricted. The Energy Independence and Security Act of 2007 changed the volume of renewable fuel to be blended into transportation fuel from 9 billion gallons in 2008 to 36 billion gallons by 2022. According to the U.S. Department of Agriculture, in 2011 over 40 percent of the U.S. corn (maize) crop was used in ethanol production. Moreover, rapidly rising standards of living in many nations, including the BRIC countries, have greatly increased the demand for agricultural products and for primary commodities such as petroleum.

As shown in Figure 1, the comovements between oil and maize prices seem to have tightened in recent years. Notably, the upward turn in real petroleum prices in the late 1990s seems to occur just prior to the rise in real maize prices. Both prices seem to decline as a result of the financial crisis in 2007. Since visual inspection can be misleading, our goal is to measure the extent to which maize prices and demand and supply shocks in the petroleum market are interrelated. The issue is important because there are conflicting policy goals between the desire for energy independence and for low food prices. That energy independence is an important policy goal is underscored by the 2006 statement of the then unknown senator from Illinois Barack Obama who declared: "It's time for Congress to realize what farmers in America's heartland have known all along - that we have the capacity and ingenuity to decrease our dependence on foreign oil by growing our own fuel" (Baltimore, 2007). However, policy makers are also concerned about the magnitude of the effect of increased biofuel use on food prices. For example, in April 2008, World Bank

\footnotetext{
${ }^{1}$ Biodiesels, particularly popular in the European Union, are made from vegetable oils and animal fats. Any linkages between such fats and maize prices are not considered here.

2Source: The U.S. Department of Energy eia.gov/cfapps/ipdbproject/iedindex3.cfm?tid=79 $\&$ pid $=79 \&$ aid $=1 \&$ cid $=$ regions\&syid $=2000 \&$ eyid=2011\&unit=TBPD. Last accessed 10/8/2014 .
} 
President Robert Zoellick declared that, "While many worry about filling their gas tanks, many others around the world are struggling to fill their stomachs. And it's getting more and more difficult every day" (Elliott and Stewart 2008). Later, in 2011, Zoellick stated, "... food prices are rising to dangerous levels and threaten tens of millions of poor people around the world" (World Bank, 2011). In the G-20 2011 winter meeting, finance ministers placed food price inflation at the top of their policy agenda. Gjelten (2011) notes that escalating food prices sparked the widespread movement for democratic reforms throughout much of North Africa and the Middle East.

\section{Remark 1 Figure 1 about Here}

Unfortunately, an econometric examination of the interrelationship between grain and oil prices is not straightforward because the linkages between the two markets have been subjected to gradual shifts. The increasing ethanol requirements of the Energy Independence and Security Act are best modeled as a gradual shifts rather than a sharp break. Moreover, the rise in the demand for primary products and foods in the BRIC countries is more likely to be captured by a smooth shift than by a sharp break. The fact that linear specifications are inappropriate to capture the relationship between oil and grain prices has been well-recognized in the literature. For example, Balcombe and Rapsomanikis (2008) and Serra et al. (2011) examine the linkages between oil prices and maize (and/or sugar) prices in a vector error-correction model (VECM) allowing for asymmetric speeds of adjustment. Similarly, Zhang et al. (2009) estimate the interrelationships among maize, soybeans, ethanol, gasoline, and oil prices in a VECM allowing for multivariate generalized autoregressive heteroskedasticity. Enders and Holt (2012) use an equation-by-equation approach to estimate the break dates 16 for commodity prices including those of petroleum, maize, soybeans and rice. The methodology employs models with sharp breaks, as in Bai and Perron (1998), and smooth breaks. Enders and Holt (2014) estimate two different types of vector autoregressions (VARs) allowing for several different types of intercept smooth shifts.

Our methodology begins with the basic VAR model of oil prices, oil production, and world output developed by Kilian (2009). Kilian (2009) breaks the key determinants of the real price of crude oil into three components: crude oil supply shocks, shocks to the global demand for all industrial commodities, and demand shocks that are specific to the global crude oil market. In the process, Kilian (2009) also develops a new measure of monthly global real economic activity. This index of global real economic activity is composed of freight rates available in the monthly report on "Shipping Statistics and Economics" published by Drewry Shipping Consultants Ltd and is based on bulk dry cargoes consisting of grain, oilseeds, coal, iron ore, fertilizer, and scrap metal. He uses these three variables (oil prices, production and global economic activity) in an exactly identified, albeit linear, VAR of the world energy market. We propose two additions to Kilian's (2009) model of the crude energy market. First, we add a fourth variable to Kilian's (2009) model (the real price of maize) in order to analyze how the petroleum and biofuels markets interact with each other controlling for world output changes. Secondly, we allow the Flexible Fourier Form to capture the 
multiple smooth mean shifts that are likely to be present in the VAR system. In a sense, our results complement those of Enders and Holt (2014) who estimate a VAR with LSTAR mean shifts. While they focus on long-run mean shifts, we focus on Granger-causality tests and on the short-run dynamics of the system. Moreover, instead of estimating a system with six breaks and three parameters per LSTAR break, our three Fourier frequencies entail the estimation of a total of six parameters.

\section{Sharp Breaks in a VAR}

As detailed in Ng and Volgelsang (2002), there can be two distinct types of breaks: additive outliers (AO) and innovational outliers (IO). In the AO model, the time series $y_{t}$ is expressed as the sum of a deterministic component and a stochastic component (say $\left.\mu_{t}\right)$. The AO model places the break in the deterministic portion of the model. In the simple case wherein the stochastic component is a first-order autoregressive process, the AO break model can be written as

$$
\begin{aligned}
& y_{t}=\delta_{0}+\delta_{m} d_{t}+\mu_{t} \\
& \mu_{t}=a_{1} \mu_{t-1}+\varepsilon_{t}
\end{aligned}
$$

where $y_{t}$ is the $n \times 1$ vector $\left(y_{1 t}, y_{2 t}, \cdots, y_{n t}\right)^{\prime}, \varepsilon_{t}$ is the $n \times 1$ vector of white-noise contemporaneously uncorrelated shocks $\left(\varepsilon_{1 t}, \varepsilon_{2 t}, \cdots, \varepsilon_{n t}\right)^{\prime}$ and $\delta_{0}$ and $a_{1}$ are $n \times 1$ and $n \times n$ parameter vectors, respectively. For our purposes, the key feature of the model is the $m \times 1$ vector of dummy variables $d_{t}=\left(d_{1 t}, d_{2 t}, \cdots, d_{m t}\right)^{\prime}$ where $d_{i t}$ is the Heaviside indicator $d_{i t}=1\left(t<t_{i}\right)$, $\delta_{m}$ is the vector of coefficients, and $\delta_{i m}$ indicates the magnitude of the effect of break $m$ on variable $i$.

Transforming (1) and (2) into a VAR in standard form

$$
y_{t}=c_{0}+a_{1} y_{t-1}+c_{1} d_{t}+c_{2} \Delta d_{t}+\varepsilon_{t}
$$

where $c_{0}=\left(I-a_{1}\right) \delta_{0}, c_{1}=\left(I-a_{1}\right) \delta_{m}, c_{2}=a_{1} \delta_{m}$, and $\Delta d_{t}=d_{t}-d_{t-1}$.

The hallmark of the innovative outlier (IO) specification is that the break occurs in the stochastic portion of the specification for $y_{t}$. Hence, in contrast to (1) and (2), the first-order IO model can be written as

$$
\begin{aligned}
& y_{t}=\delta_{0}+\mu_{t} \\
& \mu_{t}=a_{1} \mu_{t-1}+\delta_{m} d_{t}+\varepsilon_{t}
\end{aligned}
$$

Now, if we transform (4) and (5) into a VAR in standard form we have

$$
y_{t}=c_{0}+a_{1} y_{t-1}+\delta_{m} d_{t}+\varepsilon_{t}
$$

where $c_{0}=\left(I-a_{1}\right) \delta_{0}$.

The essential differences between the AO and the IO model are clear. In the AO model, mean shifts bear their full weight on $y_{t}$ immediately whereas in the IO model they are spread 
out over time. This means that it may be more difficult to detect a mean shift in IO models using a dummy variable approach. Moreover, for the AO model, estimating (6) without $\Delta d_{t}$ entails the estimation of a misspecified model.

Bai and Perron (1989) show how to estimate and test for the presence of multiple sharp structural breaks in a univariate time series model. The situation is more complicated in a VAR because a break in one variable ( say $y_{1 t}$ ) has the potential to cause mean shifts in all of the other variables. As such, it becomes difficult to determine whether breaks in the other variables in the model are due to the shift in $y_{1 t}$ or to changes in the parameters of their own data generating processes. The problem is exacerbated because the break in $y_{1 t}$ can affect the other variables with a lag. Thus, a break in $y_{1 t}$ at $t$ may manifest itself in the other variables at some future date $t+j$. To take a simple example, consider IO breaks within a 2-variable VAR in structural form so that each variable depends on the contemporaneous value of the other:

$$
\begin{aligned}
& y_{1 t}=\delta_{10}+\delta_{11} d_{1 t}+a_{1} y_{2 t}+\alpha_{11} y_{1 t-1}+\alpha_{12} y_{2 t-1}+\varepsilon_{1 t} \\
& y_{2 t}=\delta_{20}+\delta_{22} d_{2 t}+a_{2} y_{1 t}+\alpha_{21} y_{1 t-1}+\alpha_{22} y_{2 t-1}+\varepsilon_{2 t}
\end{aligned}
$$

where $\varepsilon_{1 t}$ and $\varepsilon_{2 t}$ are $i . i . d$. contemporaneously uncorrelated errors, the $a_{i}, \delta_{i j}$ and $\alpha_{i j}$ are parameters, and the Heaviside indicator functions $d_{i t}$ denote one-time shifts at $t=t_{i} \cdot{ }^{3}$ The key point to note from (7) and (8) is that the reduced form for each variable will depend on $d_{1 t}$ and on $d_{2 t}$. As such, each series can exhibit two types of shifts in its mean. At $t_{1}$ there is a shift in the means that emanates from the break in $y_{1 t}$ and at $t_{2}$ there is a change in the means that are due to the break in $y_{2 t}$. Of course, if $t_{1}=t_{2}$, the variables are said to "coshift." Now suppose that $a_{2}=0$ so that $a_{2} y_{1 t}$ affects $y_{2 t}$ with a one period lag. In such a circumstance, a break in $d_{1 t}$ will manifest itself in the $y_{2 t}$ series with a delay of one-period.

The consequences of neglecting either AO or IO mean shifts within a VAR are clearly laid out in $\mathrm{Ng}$ and Vogelsang (2002). Given that the model is misspecified when either $d_{1 t}$ or $d_{2 t}$ is ignored, it should not be surprising that the estimates of all of the included coefficients are inconsistent. For our purposes, the key result is that Granger causality tests are improperly sized; there is a bias towards a rejection of the null hypothesis of non-causality even when the null is correct. The problem is that the neglected mean shifts can manifest themselves as non-zero values in the off-diagonal elements of the $a_{1}$ matrix.

The econometric question is how to control for the breaks when the number and form of the breaks are unknown. It is important to know whether the breaks are of the AO or IO variety. The selection of the IO specification (6) when the data-generating process (DGP) is AO entails a specification error. The choice of the AO specification (3) when the DGP is IO results in the unnecessary estimation of the parameter $c_{2}$ in (3). Not only can breaks be

\footnotetext{
${ }^{3}$ Throughout the paper, we follow the usual convention and constrain the break(s) to occur only in the intercept terms. As such, we consider the type of breaks that are typically called "level shifts." Of course, a break in $\alpha$ will also cause the mean of $y_{t}$ to change.
} 
$\mathrm{AO}$ or IO but it is quite reasonable to suppose that the breaks are actually smooth. The use of an incorrect functional form to control for breaks may be worse then neglecting the breaks altogether.

\section{Using the Flexible Form to Control for Breaks}

Instead of estimating the number, form, and the size of the breaks, we use a variant of Gallant's (1981) Flexible Fourier Form to control for breaks in a VAR. Consider a VAR in which there are multiple breaks so that the deterministic part of the equation for variable $y_{i t}$ is given by

$$
d_{i t}=\delta_{i 0}+\delta_{i 1} d_{1 t}+\delta_{i 2} d_{2 t}+\cdots+\delta_{i m} d_{m t}
$$

where: $m$ is the number of breaks in variable $i$, the various $d_{i t}$ now represent potentially smooth functions of time, and the $\delta_{i j}(j=1, \cdots, m)$ are parameters indicating the magnitude of the effect of break $j$ on variable $i{ }^{4}$

If the breaks are sharp, the breaks can be represented by Heaviside indicators such that $d_{j t}=1$ if $t>t_{j}$ and $d_{j t}=0$ otherwise. As such, it is possible to use dummy variables to estimate the break dates and the magnitudes of the breaks. However, if the $d_{j t}$ are smooth functions of time, an alternative methodology is necessary. It is well known that a Fourier series approximation can capture the behavior of any absolutely integrable function. As such, it seems reasonable to use a simplified version of Gallant's (1981) Flexible Fourier Form to represent the deterministic portion of the variable $y_{i t}$

$$
d_{i t}=a_{i 0}+\sum_{k=1}^{n} a_{i k} \sin (2 \pi k t / T)+\sum_{k=1}^{n} b_{i k} \cos (2 \pi k t / T)
$$

Gallant (1987) calls this estimator "semi-nonparametric" in that it is a smooth estimator such that all of the coefficients can be obtained parametrically. The fact that breaks occur at the low end of the spectrum means that the value of $n$ should be small. More recently, a large literature has developed [see, for example Astill et al. (2014), Becker, Enders, and Lee (2006), Rodrigues and Taylor (2012), and Enders and Holt (2012)] demonstrating that a small number of low frequency components from a Fourier approximation can capture the essential characteristics of a series containing structural breaks. Figure 2 illustrates the ability of a small number of trigonometric terms to capture the essential features of a variety of breaks. The dotted lines in the figure show how a single trigonometric frequency with $k=1$ can mimic the breaks while the dashed lines show how two frequencies (i.e., $n=2$ ) can mimic the breaks. The dotted and dashed lines are the fitted values from regressing a time trend and the trigonometric terms on the actual breaks. Note that the use of a single frequency often does quite well in mimicking the break while the second frequency can help to capture any sharpness of the break. As discussed in detail in Section 4, the six breaks shown in the figure for $T=500$ are (1) a temporary break (i.e., two completely offsetting

\footnotetext{
${ }^{4}$ We do not restrict the number of breaks to be equal across equations.
} 
breaks), (2) a break with a change in the slope at T/2, (3) an LSTAR break, (4) an ESTAR break, (5) partially offsetting LSTAR breaks, and (6) partially offsetting ESTAR breaks.

The key point is that the flexible Fourier form can mimic the nature of the breaks without knowing the size of the breaks, the break dates, or the number of breaks. In a sense, the issue of controlling for breaks is transformed into the choice of the appropriate frequencies to include in the model. However, since breaks manifest themselves at the low end of the spectrum, it is possible to mimic the behavior of the breaks with a small number of low frequency trigonometric components.

There are several advantages to using a Fourier approximation to mimic the breaks. Gallant and Souza (1991) show that the $a_{i k}$ and $b_{i k}$ in (10) have a multivariate normal distribution. $^{5}$ Hence, tests for nonlinearity can be conducted using a standard $t$-test or $F$-test. Moreover, the trigonometric frequencies form an orthogonal basis in that $\sin (2 \pi k t / T)$ and $\cos (2 \pi k t / T)$ are orthogonal to each other for all integer values of $k$. This means that testing whether any or all of the $a_{i k}$ or $b_{i k}$ in (10) jointly equal zero is straightforward in that the regressors are uncorrelated with each other. Another advantage over other approximations, such as a Taylor expansion in time, time $^{2}$, time $^{3}, \cdots$ is that the trigonometric frequencies do not explode in that each is bounded in $[-1,1]$. It is also interesting to note that Fourier approximation works regardless of whether the variables are IO or AO. If the variables are IO, the one-step VAR is correctly specified. However, since $d \sin (x) / d x=\cos (x)$ and $d \cos (x) / d x=-\cos (x)$, the expression $\Delta d_{t}$ does not need to be included in the one-step procedure for finding a break.

\section{Remark 2 Figure 2 About Here}

The key issue in using the Fourier approximation is to select the appropriate frequencies to include in the model. In single equation studies, the recommendation is to use a small value of $n$ (say 2 or 3 ) to capture breaks since adding additional frequencies entails a loss of power. As such, we adopt this recommendation in a VAR setting and allow the deterministic regressors in each equation to have the form (10) where $n \leq 3$.

\subsection{Fourier Approximations and Pretesting for Unit Roots}

As a preliminary step before estimating the VAR, it seems reasonable to test whether or not the series are stationary around a smoothly changing mean (or trend). Enders and Lee (2012a, 2012b) modify the traditional Dickey-Fuller (DF) test to include trigonometric components. Consider the following equation for variable $y_{i t}$ :

$$
\Delta y_{i t}=d_{i t}+\rho y_{i t-1}+\sum_{i=1}^{p} \Delta \beta_{i} y_{i t}+\varepsilon_{i t}
$$

where $d_{i t}$ is given by (10) with $n \leq 3$ and $\varepsilon_{i t}$ is a white-noise disturbance.

\footnotetext{
${ }^{5}$ Astill et al. (2014) develop a test for the presence of deterministic Fourier components in a univariate time series model that is asymptotically robust to the order of integraton of the process in question.
} 
The coefficient of interest is $\rho$; if $y_{i t}$ is stationary around a smoothly evolving intercept, it must be the case that $-2<\rho<0$. The critical values for the test depend on whether or not a time trend is included in the model and whether the test is performed as in (11) and whether the more powerful LM version of the test is used.

Tests for linearity can be conducted by using an $F$-test to determine whether all values of $a_{i k}$ and $b_{i k}$ equal 0 . However, the distributions of the $F$-statistic is not standard and are reported in Enders and Lee (2012a) for the LM version of the test and in Enders and Lee (2012b) for the DF version of the test.

Since the LM-version of the test has more power than the DF-version of the test, we also follow Enders and Lee (2012a) and estimate

$$
\Delta y_{t}=a_{i 0}+\sum_{k=1}^{n} a_{k} \sin (2 \pi k t / T)+\sum_{k=1}^{n} b_{k} \cos (2 \pi k t / T)+v_{t}
$$

Next, using the estimates from (12), the detrended series $\widetilde{S}_{t}$ is constructed using

$$
\widetilde{S}_{t}=y_{t}-\widehat{a}_{i 0} t-\sum_{k=1}^{n} \widehat{a}_{i k} \sin (2 \pi k t / T)+\sum_{k=1}^{n} \widehat{b}_{i k} \cos (2 \pi k t / T)
$$

The testing regression is based on the detrended series

$$
\Delta y_{t}=\phi \widetilde{S}_{t}+d_{0}+\sum_{k=1}^{n} d_{1 i} \Delta \sin (2 \pi k t / T)+\sum_{k=1}^{n} d_{2 i} \Delta \cos (2 \pi k t / T)+\varepsilon_{t}
$$

If the series $y_{t}$ is stationary, it must be the case that $\phi=0$. In the case of serially correlated errors, it is recommended to use lagged values of $\Delta \widetilde{S}_{t-i}$.

\section{Monte Carlo Simulations}

We structure our Monte Carlo simulations to be as consistent as possible to those of $\mathrm{Ng}$ and Volgelsang (2002). Hence, even though our method is designed to work in the case of multiple breaks, we maintain the structure of a two-variable VAR such that there are no more than two breaks in the system. When the break dates are known, their recommended procedure (i.e., their two-step univariate two-break or 2SU2B procedure) is to obtain the OLS residuals (called $\hat{y}_{i t}$ ) from the regression of $y_{i t}$ on the deterministic regressors. If the break dates are unknown, they can be estimated using the standard Bai-Perron (1998) procedure. In either case, regress each $y_{i t}$ on the break indicator functions as in (9) so as to obtain the residual series $\hat{y}_{i t}$ :

$$
y_{i t}=\delta_{i 0}+\delta_{i 1} d_{1 t}+\delta_{i 2} d_{2 t}+\hat{y}_{i t}(i=1,2)
$$

Notice that this specification differs from that of the VAR in that neither the lagged values of $y_{1 t}$ or $y_{2 t}$ appear in the equations used to estimate the break dates. As such, 
the values of the $\hat{y}_{i t}$ series are likely to be serially correlated. Although $\mathrm{Ng}$ and Volgelsang (2002) recommend using the sequential method to estimate the number of breaks in the system, we use the simultaneous method. Prodan (2008) shows that the sequential method is problematic since the estimating equations for the first break are misspecified when there are actually two or more breaks. The problem is especially acute when the breaks are offsetting as in a system with U-shaped breaks. For the second step of the 2SU2B method, $\mathrm{Ng}$ and Volgelsang (2002) suggest estimating a VAR in the form:

$$
\begin{aligned}
& \hat{y}_{1 t}=\alpha_{11} \hat{y}_{1 t-1}+\alpha_{12} \hat{y}_{t-1}+\varepsilon_{1 t} \\
& \hat{y}_{2 t}=\alpha_{21} \hat{y}_{t-1}+\alpha_{22} \hat{y}_{2 t-1}+\varepsilon_{2 t}
\end{aligned}
$$

\subsection{Size of theTests}

To get a sense of the size of the the Flexible Fourier form in a VAR, we generated a VAR using:

$$
\begin{aligned}
& y_{1 t}=\alpha_{11} y_{1 t-1}+\alpha_{12} y_{2 t-1}+\varepsilon_{1 t} \\
& y_{2 t}=\alpha_{21} y_{1 t-1}+\alpha_{22} y_{2 t-1}+\varepsilon_{2 t}
\end{aligned}
$$

where $\varepsilon_{1 t}$ and $\varepsilon_{2 t}$ are $i . i . d$. mutually uncorrelated random variables each with a unit variance. As such, there are no breaks in either of the series. For our first set of simulations, we use six parameter sets for the $\alpha_{i j}$ such that $\alpha_{11}=\alpha_{22}$ and $\alpha_{12}=\alpha_{21}$. Specifically, each parameter set, $A_{k}=\left[\alpha_{i i}, \alpha_{i j}\right]^{T}(k=1, \ldots, 6)$, is given by:

$$
A_{1}=\left[\begin{array}{l}
0.0 \\
0.0
\end{array}\right] A_{2}=\left[\begin{array}{l}
0.5 \\
0.3
\end{array}\right] A_{3}=\left[\begin{array}{l}
0.6 \\
0.2
\end{array}\right] A_{4}=\left[\begin{array}{l}
0.6 \\
0.3
\end{array}\right] A_{5}=\left[\begin{array}{l}
0.7 \\
0.2
\end{array}\right] A_{6}=\left[\begin{array}{r}
0.6 \\
-0.3
\end{array}\right]
$$

We chose these parameter sets as Ng and Volgelsang (2002) use the single parameter set $\alpha_{i i}=0.6$ and $\alpha_{i j}=0.3$. Parameter set $A_{1}$ is such that there is not Granger-causality whereas there is bidirectional causality in each of the other parameter sets. For each generated series we alternatively fixed the value of $n$ at 1,2 or 3 and then estimated a model in the form:

$$
y_{i t}=\alpha_{i 1} y_{1 t-1}+\alpha_{i 2} y_{2 t-1}+\sum_{k=1}^{n}\left[a_{i k} \sin (2 \pi k t / T)+b_{i k} \cos (2 \pi k t / T)\right]+\varepsilon_{i t}
$$

For each estimated series, we performed two different types of tests. For the first test, we determined whether the value of $\alpha_{i j}=0$ using a standard $t$-distribution. Clearly, for $i \neq j$, this is the test for Granger-causality. The issue is whether the presence of the trigonometric terms interferes with the causality test when there are no actual breaks in the system. For the second test (called the trig-test), we perform a simple $F$-test for the exclusion restriction that all values of $a_{i k}=b_{i k}=0$. The process was repeated 5000 times alternatively using values of $n=1,2$, and 3 . The results using a prob-value of 0.10 for sample sizes of $T=250,500$, and 1000 are shown in Panels $a, b$, and $c$ of Table 2. Note 
that the columns labeled $F(i)$ and $G C(i)$ represent the $F$-tests and Granger-causality tests using frequencies $n=i$.

Notice that the empirical size of the Granger causality tests are always very close to the nominal size of 0.10 . For example, setting $T=250$ and using parameter set $A_{1}$, we rejected the null hypothesis that $\alpha_{i j}=0$ in $10.5 \%, 10.8 \%$, and $9.5 \%$ of the 2500 replications for

$n=1,2$, and 3 , respectively. The size of the $F$-test for the null hypothesis that all values of the $a_{i k}=b_{i k}=0$ is also quite reasonable. Specifically, we rejected the null hypothesis of nonlinearity in $11.4 \%, 11.6 \%$ and $11.5 \%$ of the replications for $n=1,2$, and 3 , respectively.

For parameter set 2, the Granger-causality tests were correct in almost all instances (with $n=1$ and 3, the power is $100 \%$ and for $n=2$, the power is $99.9 \%$ ). Notice that power of the causality test declines as the value of $\alpha_{i j}$ decreases in that the power is smallest for parameter sets 3 and 5 . The results also suggest that increases in $n$ act to produce a decline in the power of the test. Moreover, the power of the causality test seems to decline as the level of persistence (as measured by the largest characteristic root) increases. Panels $b$ and $c$ of the table contain the results for $T=500$ and $T=1000$.

It is important to point out that the results in Panels $a, b$, and $c$ of Table 2 use a fixed value for $n$ in that $n$ is prespecified at 1,2 , or 3 . If the $F$-test for the restriction that all values of $a_{i k}=b_{i k}=0$, is rejected, it may be possible to improve on results shown in Panels $a, b$, and $c$ of the table by testing whether the individual values of $a_{i k}=b_{i k}=0$. For example, if $n$ is initially set equal to 3 , it seems reasonable to test the restriction $a_{i 3}=b_{i 3}=0$. If it is not possible to reject the null hypothesis, conclude that $n$ is no greater than 2, and perform the test for $a_{i 2}=b_{i 2}=0$. Results using this successive application of this general-to-specific testing methodology are shown in Panels $d$, $e$, and $f$ of Table 2 . We began using a maximum value of $n=3$, and tested down until we were not able to reject the null hypothesis $a_{i n^{*}}=b_{i n^{*}}=0$. The values of $n^{*}$ along with the results of the Granger-causality test using the $n^{*}$ frequencies are reported in the table. Interestingly, the results of the Granger-causality test are hardly affected although the size of the trig-test is improved in that the number of frequencies used in the test can be pared down.

\subsection{Power of the Test with Sharp Breaks}

Perhaps the more important issue is to ascertain how the trig-test performs in the presence of structural breaks in the data-generating process. We begin by using break proportions $\lambda_{1}=1 / 3$ and $\lambda_{2}=2 / 3$ that roughly correspond to those of $\mathrm{Ng}$ and Vogelsang (2002) and by selecting the following five sets for the $\alpha_{i j}$ :

$$
\begin{gathered}
A_{7}=\left[\begin{array}{ll}
0 & 0 \\
0 & 0
\end{array}\right] ; A_{8}=\left[\begin{array}{ll}
0.6 & 0.0 \\
0.0 & 0.6
\end{array}\right] ; A_{9}=\left[\begin{array}{ll}
0.6 & 0.0 \\
0.3 & 0.6
\end{array}\right] ; \\
A_{10}=\left[\begin{array}{ll}
0.6 & 0.3 \\
0.3 & 0.6
\end{array}\right] ; A_{11}=\left[\begin{array}{cc}
0.6 & -0.3 \\
-0.3 & 0.6
\end{array}\right]
\end{gathered}
$$


Unlike the previous simulation, the goal here is to assess whether the Granger-causality test is oversized in the presence of breaks that are approximated by a Fourier function. As such, parameter sets $A_{7}, A_{8}$, and $A_{9}$ contain zeroes in position $\alpha_{12}$. If the trigonometric terms properly mimic the breaks, we should expect to find Granger-causality present in the $\left\{y_{1 t}\right\}$ series for parameter sets $A_{10}$ and $A_{11}$ and not for $A_{7}, A_{8}$, and $A_{9}$. In order to examine the case wherein the breaks act as innovative outliers, we augment the equation for $y_{1 t}$ with $d_{1 t}$ and the equation for $y_{2 t}$ with $d_{2 t}$ where $d_{i t}$ represents a $(0,1)$ indicator function such that $d_{i t}=0$ if $t \leq \lambda_{i} T$ and 1 otherwise. Hence, for the case of innovative outliers, the specification for the DGP becomes:

$$
\begin{aligned}
& y_{1 t}=d_{1 t}+\alpha_{11} y_{1 t-1}+\alpha_{12} y_{2 t-1}+\varepsilon_{1 t} \\
& y_{2 t}=d_{2 t}+\alpha_{21} y_{1 t-1}+\alpha_{22} y_{2 t-1}+\varepsilon_{2 t}
\end{aligned}
$$

Although the generated series all contain sharp breaks, we continue to use a Fourier approximation to capture the essential features of the breaks. Hence, for each generated series we estimate a model in the form of (21) so that for each series we estimate:

$$
y_{i t}=\alpha_{i 1} y_{1 t-1}+\alpha_{i 2} y_{2 t-1}+\sum_{k=1}^{n}\left[a_{i k} \sin (2 \pi k t / T)+b_{i k} \cos (2 \pi k t / T)\right]+\varepsilon_{i t}
$$

for $n=1,2$, and 3 .

Given the results of the first simulation, we simply fix $n$ at 1,2, or 3 and do not attempt to pare down the trigonometric frequencies using the general-to-specific testing methodology. Since each series contains a single structural break, we should find that the sample $F$ statistics allow us to reject the null hypothesis that all values of $a_{i k}=b_{i k}=0$. The results for the $\left\{y_{1 t}\right\}$ series are shown in Panels $a, b$, and $c$ of Table 3 for a prob-value of 0.10. For a sample size of $T=250$, the power of the trig-test exceeds $80 \%$ for parameter sets 7 through 10 but is only $55.1 \%$ for parameter set 11 . As shown in the lower portion of the table, the performance of the trig-test improves as the sample size increases. Table 3 also contains the results of the Granger-causality tests. For the case of $T=250$ and $n=1$, the empirical sizes of the Granger-causality tests are 10.7\%,10.2\%,10.8\%,100\% and 100\% for parameter sets 7 through 11, respectively. Increasing the number of frequencies tends to increase the number of instances that incorrectly indicate causality; for $n=3$, the empirical size is $15.2 \%$ and $12.4 \%$ for parameter sets 8 and 9 . If you compare the results if Panels $b$ and $c$ to those of Panel $a$, it should be clear that the performance of the Granger-causality tests and the trig-tests improve as the sample size increases.

The specification for the case of additive outliers is given by:

$$
\begin{aligned}
& y_{1 t}=x_{1 t}+d_{1 t} ; \text { where } x_{1 t}=\alpha_{11} x_{i t-1}+\alpha_{12} x_{j t-1}+\varepsilon_{1 t} \\
& y_{2 t}=x_{2 t}+d_{2 t} ; \text { where } x_{2 t}=\alpha_{21} x_{1 t-1}+\alpha_{22} x_{2 t-1}+\varepsilon_{2 t}
\end{aligned}
$$

Since the breaks are simply "added" onto the VAR, the breaks in the additive outlier case appear to be sharper than those for innovative outliers. The results for the additive outlier 
specification are shown in Panels $d, e$ and $f$ of Table 3. Notice that the Granger-causality results are reasonably similar to those of the case for an innovative outlier. For the case of $T=250$, the table indicates that for $n=1$, the empirical sizes of the Granger-causality tests are $10.7 \%, 10.2 \%, 11.6 \%, 100 \%$, and $100 \%$ for parameter sets 7 through 11 , respectively. Nevertheless, the power of the trig-test is relatively low. Intuitively, as the breaks become more sharp, the performance of the test is anticipated to decline. However, if the goal is to properly assess the presence of Granger-causality, the use of a Fourier approximation to control for breaks of an unknown form seems to be quite reasonable.

\subsection{Power of the Test with Smooth Breaks}

The types of breaks considered above put the trig-test in its worst light given that a trigonometric approximation is designed to work best in the presence of multiple smooth breaks. As such, we now consider the types of breaks shown by the solid lines in the six panels of Figure 2. The dotted lines show how a single trigonometric frequency with $k=1$ can mimic the breaks while the dashed lines show how two frequencies (i.e., $n=2$ ) can mimic the breaks. The dotted and dashed lines are the fitted values from regressing a time trend and the trigonometric terms on the actual breaks. Note that the use of a single frequency often does quite well in mimicing the break while the second frequency can help to capture any sharpness of the break. The seven breaks we use in our simulations are the same as those used to create Figure 2. In order that the breaks not vanish as the sample size $T$ increases, we include the parameter $w=T / 500$ so that the breaks are:

1. Temporary break: In Panel $a$ there is a temporary break (or what can be thought of as two offsetting breaks). Specifically, the breaks are such that $d_{1 t}=0$ if $0.45 T<$ $t \leq 0.75 T$ and $d_{1 t}=3$ if $t \leq 0.45 T$ or if $t>0.75 T$.

2. Change in Slope: The series in Panel b is such that at $T / 2$ the slope declines such that $d_{1 t}=-0.80+0.015 t / w$ for $t<T / 2$ and $d_{1 t}=2.28+0.0025 t / w$ for $t \geq T / 2$. Note that the intercept is also adjusted so that the function is continuous at the break date.

3. LSTAR Break: Break type 3, shown in Panel c, is a smooth logistic break in that $d_{1 t}=3 /[1+\exp ((0.05 / w)(t-2 T / 3)]$. Hence, for small values of $t$, the intercept is approximately 3 and for very large $t$, the intercept is approximately 0 . Note that the centrality parameter is $2 T / 3$ and that $w=T / 500$. The rationale for including the expression $w$ is to normalize the speed of adjustment term whenever we compare results using different sample sizes.

4. ESTAR Break: Panel d shows an exponential break such that $d_{1 t}=3[1-\exp (-0.0002$ $\left.\left(1 / w^{2}\right)(t-2 T / 3)^{2}\right]$ where $w=T / 500$. Hence, for very small and large values of $t$, the intercept is approximately 3 whereas, for $t$ near $2 T / 3$, the intercept is approximately 0 . 
5. Partially Offsetting LSTAR Breaks: Break type 5 entails two LSTAR breaks that act to offset each other in that $d_{1 t}=2+3 /[1+\exp ((0.05 / w)(t-0.2 T))]-1.5 /[1+$ $\exp ((0.05 / w)(t-0.75 T))]$ where $w=T / 500$. For small positive values of $t, d_{1 t}$ is about 3.5 , rises towards 0.5 as $t$ increases and falls toward 2 for large $t$.

6. Offsetting ESTAR Breaks: Break type 6 contains two ESTAR breaks that act to offset each other in that $d_{1 t}=2+1.8\left[1-\exp \left(-0.0003\left(1 / w^{2}\right)(t-T / 5)^{2}\right)\right]-1.5 /[1-$ $\left.\exp \left(0.0003\left(1 / w^{2}\right)(t-0.75 T)^{2}\right)\right]$. Here, the intercept declines from almost 2.3, reaches a minimum of about 0.5 at $T / 5$, and rises to about 2.3 again. As the influence of the second break manifests itself, the intercept rises toward a maximum of about 3.8 at $t=3 / 4 T$ and then declines toward 2.3 .

7. A trigonometric Break: Break type 7 (not shown in Figure 2) contains a purely sinusoidal break such that the frequency is 2 . Note that this differs from the case of cumulative frequencies such that $n=2$ (since trigonometric terms with $k=1$ are not included). In particular, break 2 is the trigonometric expression $d_{1 t}=2+\sin (4 \pi t / T)+$ $\cos (4 \pi t / T)$. Since $k=2$, there are two complete cycles over the interval $t=1, \ldots, T$.

We allow $\left\{y_{1 t}\right\}$ to contain one of the breaks indicated above and constrain $\left\{y_{2 t}\right\}$ to contain the single sharp break $d_{2 t}=3$ if $0<T / 3$ and 0 otherwise. As such, one of the breaks is always sharp even though the performance of the test is enhanced when both breaks are smooth. The results of applying the trig-test and the Granger-causality test for $T=250$ are shown in Table $4{ }^{6}$ There are several key points to notice about the results. In particular, when the breaks are simply ignored (so that no frequencies are included in the estimating equations), the column indicated $\mathrm{GC}(0)$ indicates that the test for Grangercausality is usually poorly sized. For example, in the absence of causality and when break type 1 acts as an innovative outlier, the empirical size of the Granger-causality test is 0.686 , 0.438 , and 0.751 for parameter sets $A_{7}, A_{8}$, and $A_{9}$, respectively. Interestingly, for parameter set $A_{11}$ (in which there is Granger-causality) the test is severely undersized in that causality was found in only $42.9 \%$ of the Monte Carlo replications. If you examine the other entries under the heading $\mathrm{GC}(0)$, it should be clear this result is not specific to the break type or to whether the break acts as an innovative or an additive outlier.

Perhaps the most important result is that the incorporation of one or two frequencies into the estimating equation substantially improves the power of the causality tests. Even in the case of an innovative sharp temporary break (i.e., break type 1), with parameter set $A_{7}$, the size of the test is 0.137 with a single frequency, 0.136 with a second frequency, and 0.119 with $n=3$. However, as illustrated by parameter set $A_{9}$, the incorporation of a third frequency does not always improve the size of the Granger-causality test. Given the results in the simulations, we find that in a small system (i.e., one with two variables) with a small

\footnotetext{
${ }^{6}$ Results for $T=100$ and $T=500$ are contained in an unpublished Appendix.
} 
number of breaks, the use of two frequencies seems to provide a good balance in that a single frequency and a third frequency can lead to an oversized test. ${ }^{7}$

Notice that the Granger-causality test has very poor performance in three instances. When the temporary break acts as an additive outlier, with parameter sets $A_{7}, A_{8}$, and $A_{9}$, the size of the test exceeds $20 \%$ regardless of the number of frequencies used. Obviously, this is because the breaks are especially sharp and the use of trigonometric functions does not approximate the breaks especially well. Also, the causality test performs poorly with the use of a single frequency in the presence of an ESTAR break. As shown in Panel d of Figure 2, a single frequency does not capture the sharpness of this U-shaped ESTAR break at $2 T / 3$. Thirdly, with the trigonometric break $d_{1 t}=2+\sin (4 \pi t / T)+\cos (4 \pi t / T)$, the use of a single frequency results in very poor performance. Obviously, since a single trigonometric component with $k=1$ is orthogonal to a trigonometric term with $k=2$, we should anticipate poor performance in this case. However, the test works quite well when $n=2$ since the second frequency component perfectly mimics the actual break in $\left\{y_{1 t}\right\}$. The point is that improperly modeling the form of the breaks may do little to improve the performance of causality tests.

Table 5 repeats the exercise reported in Table 4, but with one important difference. Instead of assuming that the error terms are uncorrelated across equations, we now assume that the contemporaneous correlation between $\varepsilon_{1 t}$ and $\varepsilon_{2 t}$ is 0.5 . When the errors are strongly correlated and the breaks are sharp, is difficult to differentiate between the influence of a break in $y_{2 t}$ and shocks to $\varepsilon_{2 t}$ on the $\left\{y_{1 t}\right\}$ series. In comparing Tables 4 and 5 , notice that the size of the Granger-causality tests deteriorate substantially when the breaks are sharp. For example, with break type 1 , the test is seriously oversized for $n=1,2$, or 3 . It is also quite oversized for $n=2$ with break types 5 and 6 . Nevertheless, as can be seen from the table, adding a third frequency is often helpful. So long as the breaks are smooth, the results reported in Tables 4 and 5 are fairly close.

\subsection{Estimating Smooth Breaks as Sharp Breaks}

Although the use of Fourier terms can, at times, be problematic, it seems reasonable to determine how the Bai-Perron procedure fares in the presence of multiple smooth breaks. Of course, sharp breaks can capture smooth breaks using a step-function. Nevertheless, the incorporation of many sharp breaks to capture smooth shifts can entail a loss of efficiency since each break necessitates the estimation of two parameters (the break date and the coefficient of the break dummy variable). Moreover, highly persistent series can appear to have smooth shift that tend to be offsetting. To illustrate some of these issues, in our

\footnotetext{
${ }^{7}$ As discussed above, it is possible to use the general-to-specific methodology to pare down the number of frequencies included in the final estimating equation. Alternatives ways of paring down the frequencies include using a model selection criterion such as the $A I C$ or BIC. Also, since each frequency component is orthogonal to each other and the distribution of each is normal, it is possible to pare down the frequencies using a combination of $t$-tests or $F$-tests.
} 
simulations we allowed for a maximum of four breaks and a minimum span between breaks of 12 . We let the $\left\{y_{1 t}\right\}$ series contain break types 1 through 7 , let the $\left\{y_{2 t}\right\}$ series contain break type 2 , and let the correlation between $\varepsilon_{1 t}$ and $\varepsilon_{2 t}$ equal 0.5 . For break types 2 and 3 , we also allowed for the possibility of a trend break. As shown in Table 6 for a sample size of 250, when $\left\{y_{1 t}\right\}$ contains a sharp temporary break and $\left\{y_{2 t}\right\}$ contains break type 4 , the size of the Granger-causality test is quite good for parameter sets $A_{7}, A_{8}$ and $A_{9}$. Surprisingly, the test is undersized with parameter set $A_{10}$ in the it finds Granger causality in only $20.9 \%$ of the Monte Carlo trials. The entries in the columns labeled $B(0)$ through $B(4)$ indicate the proportion of the replications in which the procedure selected 0 through 4 breaks. Even when there is no persistence (i.e., with parameter set $A_{7}$ ) the Bai-Perron procedure selects the maximum number of breaks in $23.2 \%$ of the Monte Carlo replications.

Although the test can work reasonably for break type 3 (i.e., the LSTAR break at 2T/3), it works poorly for most of the other smooth breaks. For example, when we used break type 2 , the empirical size of the test was $38.4 \%, 15.3 \%$, and $40.5 \%$ with parameter sets $A_{7}, A_{8}$, and $A_{9}$, respectively. As expected, the test performance is worse with break types 6 and 7 . With break type 6 , the empirical size of the test is $21.4 \%, 33.2 \%$, and $53.4 \%$ with parameter sets $A_{7}, A_{8}$, and $A_{9}$. Moreover, the procedure almost always selects the 4 breaks (i.e., the maximum number of breaks) so as to mimic the smooth breaks using a step function.

\section{Estimation Results}

Pretests for Unit Roots: Before proceeding to the VAR, we first test whether or not the variables used in the analysis are stationary. However, instead of just using a standard augmented Dickey-Fuller test, we also test whether the variables are stationary around a slowly evolving mean. As discussed above, in order to account for the possibility of smooth breaks, we employ the DF-Fourier and the LM-Fourier unit root tests of Enders and Lee (2012a, 2012b). Specifically, as detailed in Enders and Lee (2012b), to augment the standard Dickey-Fuller test with trigonometric terms, we can estimate (11) and test the null hypothesis $\rho=0$. The sample period is $1974: 1-2012: 12$. In order to rid the residuals of any potential serial correlation, we select the number of autoregressive lag lengths in our unit root tests by minimizing the Akaike Information Criteria (AIC). Once the number of autoregressive lags is selected, we use the Schwartz Bayesian information criteria (SBC) to select the number of cumulative Fourier frequencies, $n$.

The results using the standard augmented Dickey-Fuller test are shown in the column labeled $D F$ in Table 7 . Notice that we cannot reject the null hypothesis of a unit root for any of the four series. The results are more supportive of stationarity when using the Fourier augmented Dickey-Fuller test consisting of (11) and (10). Real ocean freight rates-Kilian's (2009) measure of real economic activity-and the real price of maize are both found to be stationary at better than the $95 \%$ level. The test statistics for oil production and the real price of oil are not significant at conventional levels. 


\section{Table 7: Unit Root Tests}

\begin{tabular}{cccll} 
Series & $n$ & $D F$ & \multicolumn{1}{c}{$\tau_{D F}$} & $\tau_{L M}$ \\
prod & 1 & -1.08 & -3.88 & $-4.11^{* *}$ \\
world output & 3 & -1.67 & $-6.05^{* *}$ & $-5.65^{* *}$ \\
oil price & 1 & -1.42 & -3.95 & $-5.37^{* * *}$ \\
maize price & 2 & -2.21 & $-5.08^{* *}$ & $-4.94^{* *}$
\end{tabular}

Respectively, *, ** and *** denote statistical significance at the $90 \%, 95 \%$, and $99 \%$ levels. Respectively, $D F, \tau_{D F} \cdot \tau_{L M}$ are the appropriate t-statistics from the linear Dickey Fuller test, the test augmented with trigonometric terms and, the $L M$ version of the test. The regressions for prod allow for a linear time trend.

The last column of Table 7 reports the $L M$ test statistic for each series. All of the data series are found to be stationary around a time-varying intercept at the $95 \%$ statistical significance level or better. Since this test has more power than either of the other tests, it seems reasonable that we follow Kilian and use oil production in first-differences. ${ }^{8}$

\subsection{The Linear VAR}

Let $z_{t}=\left(\Delta \operatorname{prod}_{t}, w_{t}, p \_o i l_{t}, p \_ \text {maize }_{t}\right)^{\prime}$, where $\Delta \operatorname{prod}_{t}$ is the logarithmic change in crude oil production, $w_{t}$ is Kilian's (2009) index of world output, $p_{-}$oil $t_{t}$ is the real price of oil and $p_{\text {_ }}$ maize $_{t}$ is the real price of maize. Consider the VAR

$$
z_{t}=\delta+\sum_{i=1}^{11} A_{i} z_{t-i}+e_{t}
$$

where $\delta$ is a $(4 \times 1)$ vector of intercepts, $A_{i}$ is a $(4 \times 4)$ coefficient vector, and $e_{t}$ is the vector of innovations orthogonalized as in Kilian (2009) except for the fact that we let $\Delta$ prod $_{t}, w_{t}$, and $p_{\text {_oil }}$ be causally prior to $p_{-}$maize $_{t}$. As such

$$
\left[\begin{array}{l}
e_{t}^{\Delta \text { prod }} \\
e_{t}^{w} \\
e_{t}^{p \_o i l} \\
e_{t}^{p \_ \text {maize }}
\end{array}\right]=\left[\begin{array}{cccc}
a_{11} & 0 & 0 & 0 \\
a_{22} & a_{22} & 0 & 0 \\
a_{31} & a_{32} & a_{33} & 0 \\
a_{41} & a_{42} & a_{43} & a_{44}
\end{array}\right]\left[\begin{array}{l}
\varepsilon_{t}^{\Delta \text { prod }} \\
\varepsilon_{t}^{w} \\
\varepsilon_{t}^{p} \text { oil } \\
\varepsilon_{t}^{p \_ \text {maize }}
\end{array}\right]
$$

where $\varepsilon_{t}$ is the the $(4 \times 1)$ vector of orthogonal shocks $\left(\varepsilon_{t}^{\Delta p r o d}, \varepsilon_{t}^{w}, \varepsilon_{t}^{p+{ }^{o i l}}, \varepsilon_{t}^{p \_}{ }^{\text {maize }}\right)^{\prime}$. Since our data series contain 468 observations, we implement a general-to-specific methodology to select the proper lag length for our VAR estimation. This potentially allows a richer interaction between our series. We start with a lag length of twelve and pare down our model by eliminating insignificant lags. ${ }^{9}$

\footnotetext{
${ }^{8}$ The results using oil production are similar to those reported here and are available from the authors upon request.

${ }^{9}$ For 12 lags, the AIC and SBC are -15.894 and -14.120 whereas for 11 lags they are -15.921 and 14.291. The cross-equation restriction that the VAR lag length is 12 versus 11 has a prob-value of 0.341 and that for a lag length of 11 versus 10 is 0.040 .
} 
Figure 3 shows the impulse responses produced by a one standard deviation shock to each of the series. The first column shows the responses to a one-standard-deviation oil supply shock. The oil supply shock causes real economic activity to increase by month two and the point estimate continues to be positive through month twenty four. On the other hand, the oil supply shock decreases the real price of oil and the real price of maize. The aggregate demand shock affects the real price of oil and the real price of maize on impact and permanently raises both. Oil production is not affected by the aggregate demand shock, the oil-specific demand shock, or the maize-specific demand shock. Real economic activity initially increases after an oil-specific demand shock, but the point estimates turn negative around month ten and remain negative through month twenty four. The real price of maize initially does not respond to the oil-specific demand shock until around month five. After month five the real price of maize rises through month twenty four. Finally, the maizespecific demand shock causes real economic activity to decrease and the real price of oil to increase although neither effect is significantly different from zero.

\section{Remark 3 Figure 3 About Here}

Even though the responses seem reasonable, they are problematic for two reasons. First, to the extent that there are neglected structural breaks, the system given by (28) is misspecified. Second, given that an unrestricted VAR is likely to be overparmeterized, the confidence intervals shown in the figure may be unnecessarily large.

In order to illustrate how neglected breaks can interfere with Granger causality tests, suppose we follow a standard recommendation and pare down the VAR by imposing the restrictions implied by the Granger causality tests reported in Table 8. Notice that nothing Granger causes oil production, real economic activity, or the real price of oil. Real economic activity Granger causes maize at the 5\% level, but this is the only evidence of Granger causality present in the entire system. Therefore, there is no linkage between any part of the oil sector and maize. Once the results of the causality tests are imposed, the impulse responses look completely different from those shown in Figure 3. Not surprisingly, there is very little interaction among the four variables. The significant responses are such that (aside form the effects of $w_{t}$ on maize), series tend to respond only to their own shocks. ${ }^{10}$

\footnotetext{
${ }^{10}$ Since the variable have very little interaction, the impulse responses obtained by imposing the causality results reported in Table 2 are not shown here in order to save space.
} 


\section{Table 8: Causality Tests in the Linear System}

$\begin{array}{ccccc}\text { to/on } & \Delta \text { prod }_{t} & w_{t} & p_{-} \text {oil } & p_{-} \text {maize }_{t} \\ & & 1.18 & 0.52 & 0.45 \\ \text { srod } & - & (0.30) & (0.88) & (0.93) \\ & 1.35 & - & 1.18 & \mathbf{1 . 8 0} \\ w_{t} & (0.20) & & (0.30) & (\mathbf{0 . 0 5}) \\ & 1.25 & 1.32 & - & 1.23 \\ \text { p_oil }_{t} & (0.25) & (0.21) & & (0.26) \\ & 1.47 & 0.55 & 1.56 & - \\ \text { p_maize }_{t} & (0.14) & (0.87) & (0.11) & \end{array}$

Note: Element $a_{i j}$ is the $F$-statistic for the null that series $i$ does not Granger cause series $j$, prob-values are in parentheses.

Values in bold face indicate significance at the $5 \%$ level.

\subsection{The VAR with Fourier Frequencies}

Instead of the VAR given by (28), let the deterministic regressors be such that

$$
\begin{gathered}
z_{t}=\delta(t)+\sum_{i=1}^{11} A_{i} z_{t-i}+e_{t} \\
\delta(t)=\left[\delta_{1}(t), \delta_{2}(t), \delta_{3}(t), \delta_{4}(t)\right] \prime
\end{gathered}
$$

and each intercept $\delta_{i t}$ depends on $n$ Fourier frequencies such that

$$
\delta_{i}(t)=a_{i}+b_{i} t+\sum_{k=1}^{n} a_{i k} \sin (2 \pi k t / T)+b_{i k} \cos (2 \pi k t / T)
$$

We estimated (30) beginning with $n=3$ and tested the cross-equation restriction that all values of $a_{i 3}=b_{i 3}=0 .(i=1 \cdots n)$. Since the sample value of Rao's $F=2.99$ with a significance level of 0.0026 , we report results for $n=3$. In addition, both the multivariate AIC and SBC selected $n=3$ over $n=2$. Figure 4 shows the fitted means plotted against the actual series. Notice that oil production is plotted in levels including a time trend although the results reported below follow Kilian (2009) and use oil production in first-differences. The jagged lines represent the actual series and the smooth lines show how the Fourier frequencies capture the gradual shifts in the levels of each series. Interestingly, the most recent upward mean shift in the price of oil begins preceeds that for maize. Comparing Panels $b$ and $c$ indicates that the increase in oil prices begins in 1999 whereas that for maize begins in 2003. Moreover, oil production levels off in 2003 and world output (measured by the freight rate index) starts to decline in 2006.

Remark 4 Figure 4 About Here 
Once the Fourier terms are used to control for breaks, the Granger causality results change from those reported above in several important ways. As shown in Table 9, oil production seems to evolve autonomously in that it is not Granger-caused by any of the variables in the system. Real economic activity is Granger-caused by oil production and (at the $7 \%$ level) by the the price of maize. The real price of oil is Granger-caused by the real economic activity, and the real price of maize is Granger-caused by oil prices.

\section{Table 9: Causality Tests in the Fourier System}

$\begin{array}{ccccc}\text { to/on } & \text { sprod } & w_{t} & p_{-} \text {oil } & p_{-} \text {maize }_{t} \\ \Delta \text { prod }_{t} & - & 1.17 & 0.63 & 0.46 \\ & & (0.30) & (0.80) & (0.93) \\ w_{t} & \mathbf{1 . 8 2} & & 1.06 & 1.70 \\ & (\mathbf{0 . 0 5}) & - & (0.94) & (0.07) \\ \text { p_oil }_{t} & 0.99 & \mathbf{1 . 9 7} & & 0.91 \\ & (0.45) & (\mathbf{0 . 0 3}) & - & (0.53) \\ \text { p_maize }_{\text {_ }} & 1.15 & 0.41 & \mathbf{1 . 8 3} & -\end{array}$

Note: Element $\alpha_{i j}$ is the $F$-statistic for the null that series $i$ does not Granger cause series $j$, prob-values are in parentheses.

Values in bold face indicate significance at the $5 \%$ level.

Figure 5 shows the impulse responses produced by one-standard-deviation shocks imposing the results of the Granger causality tests reported in Table 9. As shown in Figure 5 the entire system displays much more interaction once Fourier terms are included in the analysis. A one-standard-deviation shock to real economic activity causes an increase in the real price of oil and the real price of maize. However, a one-standard-deviation shock to the real price of oil causes an increase in real economic activity for approximately three months before decreasing by approximately 0.5 standard deviations after twenty four months. The real price of maize also interacts with the real price of oil. A one-standard-deviation shock to the real price of maize causes an increase in the real price of oil. ${ }^{11}$

Remark 5 Figure 5 About Here

\section{Conclusion}

As shown in $\mathrm{Ng}$ and Vogelsang (2002) it is not straightforward to control for breaks in a VAR. Since a break in one variable will manifest itself in the other variables of the system,

\footnotetext{
${ }^{11}$ In the Appendix we report the same analysis using the level of oil production instead of the difference in oil production. The only major difference between Figure 5 and these results is that the oil supply shock is more persistent in levels than in first differences.
} 
it is difficult to account for the original source of the break. Unless breaks in a VAR are properly controlled for, the estimated model is misspecified so that all impulse responses and variance decompositions are problematic. Moreover, Granger-causality tests tend to over-reject the null hypothesis of non-causality.

In order to simplify the problem of properly estimating the number of breaks, the form of the breaks, and the break dates we proposed using a small number of low frequency components of a Fourier approximation. It was shown that the proposed methodology has reasonable size and power properties when the breaks are actually sharp. Not surprisingly, the tests generally perform much better when the breaks are smooth. It was shown that the standard Bai-Perron $(1998,2003)$ testing methodology employing sharp breaks can perform poorly when the breaks are smooth. If it is unclear as to whether the breaks are sharp or smooth, our so-called trig-tests can be used to complement the more traditional Bai-Perron tests.

Given the promising results concerning the ability of the Flexible Fourier Form to approximated breaks, we applied the method to the interrelated markets for petroleum and maize. Both markets have experienced breaks that are best modeled as smooth changes than sharp. The introduction of biofuels into ethanol production and the rising demand for primary products and foods from the BRIC countries are best represented by gradual, rather than sharp, structural breaks. In contrast to the Granger-causality results implied by Kilian's (2009) VAR, when we introduce trigonometric functions into the model, we find a richer set of interactions between the markets. In particular, we find that oil price shocks have a depressing effect on real economic activity that lasts as long as two years. Moreover, given the upswing in the utilization of biofuels, it is not surprising that we find that increases in maize prices also act to increase the price of petroleum. 


\section{References}

[1] Astill, Sam , David Harvey, Stephen Leybourne and Robert Taylor, "Robust and Powerful Tests for Nonlinear Deterministic Components," Oxford Bulletin of Economics and Statistics, 2014, onlinelibrary.wiley.com/doi/10.1111/obes.12079/pdf. Last accessed 10/30/14.

[2] Baltimore, Chris. "New U.S. Congress looks to boost alternate fuels," Reuters, January 5, 2007. http://www.reuters.com/article/2007/01/05/us-energy-congress-fuelsidUSN0525793820070105.

[3] Bai, Jushan and Pierre Perron, "Estimating and Testing Linear Models with Multiple Structural Changes," Econometrica, 1998, 66 (1), pp. 47-78.

[4] Bai, Jushan and Pierre Perron , "Computation and Analysis of Multiple Structural Change Models," Journal of Applied Econometrics, 2003, 18 (1), pp. 1-22.

[5] Becker, Ralf, Walter Enders, and Junsoo Lee, "A Stationarity Test in the Presence of an Unknown Number of Smooth Breaks," Journal of Time Series Analysis, 2006, 27 (3), 381-409.

[6] Becker, Ralf, Walter Enders, and Stan Hurn, "A General Test for Time Dependence in Parameters," Journal of Applied Econometrics, 2004, 19 (7), pp. 899-906.

[7] Balcombe, Kelvin and George Rapsomanikis, "Bayesian Estimation and Selection of Nonlinear Vector Error Correction Models: The Case of the Sugar-Ethanol-Oil Nexus in Brazil," American Journal of Agricultural Economics, 2008, 90 (3), pp. 658-668.

[8] Elliott, Larry and Heather Stewart. "Poor Go Hungry While Rich Fill Their Tanks," The Guardian, April 10, 2008. http://www.theguardian.com/business/2008 /apr/11/worldbank.fooddrinks1.

[9] Enders, Walter, Applied Econometric Time Series, 3rd ed., Hoboken, NJ: Wiley, 2010.

[10] Enders, Walter and Junsoo Lee, "A Unit Root Test Using a Fourier Series to Approximate Smooth Breaks," Oxford Bulletin of Economics and Statistics, 2012a, 74 (4), pp. $574-599$.

[11] Enders, Walter, and Junsoo Lee. "The Flexible Fourier Form and Dickey-Fuller type Unit Root Tests." Economics Letters 2012(b), 117 (1), pp. 196-199.

[12] Enders, Walter and Matthew T. Holt, "Sharp Breaks or Smooth Shifts? an Investigation of the Evolution of Primary Commodity Prices," American Journal of Agricultural Economics, 2012, 94 (3), pp. 659-673. 
[13] Enders, Walter and Matthew T. Holt, "The Evolving Relationships Between Agricultural and Energy Commodity Prices: A Shifting-Mean Vector Autoregressive Analysis." In J. P. Chavas, D. Hummels, and B. Wright, eds. The Economics of Food Price Volatility. (Chicago: University of Chicago Press). 2014. pp. 135-87.

[14] Gallant, Ronald, "On the Bias in Flexible Functional Forms and an Essentially Unbiased Form," Journal of Econometrics, 15 (2), 1981, pp. 211-245.

[15] Gallant, A. Ronald, "The Fourier Flexible Form," American Journal of Agricultural Economics, 1984, 66 (2), pp. 204-208.

[16] Gallant, A. Ronald and Geraldo Souza, "On the Asymptotic Normality of Fourier Flexible Form Estimates," Journal of Econometrics, 1991, 50 (3), 329-353.

[17] Gjelten, Tom. "The Impact of Rising Food Prices on Arab Unrest." 2011-0510]. npr.org/ 2011/02/18/133852810/the-impact-of-rising-food-prices-on-arab-unrest. (2011). Last accessed 10/12/2014.

[18] Kilian, Lutz, "Not All Oil Price Shocks Are Alike: Disentangling Demand and Supply Shocks in the Crude Oil Market," American Economic Review, 2009, 99, pp. 1053-1069.

[19] Ng, Serena and Timothy Vogelsang, "Analysis of Vector Autoregressions In the Presence of Shifts In Mean," Econometric Reviews, 2002, 21 (3), 353-381.

[20] Perron, Pierre, "The Great Crash, the Oil Price Shock, and the Unit Root Hypothesis," Econometrica, 1989, 57 (6), pp. 1361-1401.

[21] Perron, Pierre, "Further Evidence on Breaking Trend Functions in Macroeconomic Variables," Journal of Econometrics, 1997, 80 (2), pp. 355-385.

[22] Prodan, Ruxandra, "Potential Pitfalls in Determining Multiple Structural Changes with an Application to Purchasing Power Parity," Journal of Business and Economic Statistics, 2008, 26 (1), pp. 50-65.

[23] Rodrigues, Paulo and Robert Taylor, "The Flexible Fourier Form and Local Generalised Least Squares De-trended Unit Root Tests," Oxford Bulletin of Economics and Statistics, 2012, 74 (5), pp. 736-59.

[24] Serra, Teresa, David Zilberman, Jos'e M. Gil, and Barry K. Goodwin, "Nonlinearities in the U.S. Corn-Ethanol-Oil-Gasoline Price System," Agricultural Economics, 2011, 42 (1), pp. 35-45.

[25] World Bank. "Food Price Hike Drives 44 Million People into Poverty," [Press Release No:2011/333/PREM], February 15, 2011. Washington, D.C.

[26] Zhang, Zibin, Luanne Lohr, Cesar Escalante, and Michael Wetzstein, "Ethanol, Corn, and Soybean Price Relations in a Volatile Vehicle-Fuels Market," Energies, 2009, 2 (2), pp. 320-339. 
Table 2: Simulation Results

Panel a: Sample Size $=250$

\begin{tabular}{ccccccc} 
& \multicolumn{2}{c}{$n=1$} & \multicolumn{2}{c}{$n=2$} & \multicolumn{2}{c}{$n=3$} \\
\cline { 2 - 7 } Parameters & $\mathrm{F}(1)$ & $\mathrm{GC}(1)$ & $\mathrm{F}(2)$ & $\mathrm{GC}(2)$ & $\mathrm{F}(3)$ & $\mathrm{GC}(3)$ \\
$A_{1}$ & 0.114 & 0.105 & 0.116 & 0.108 & 0.115 & 0.095 \\
$A_{2}$ & 0.141 & 1.000 & 0.164 & 0.999 & 0.230 & 1.000 \\
$A_{3}$ & 0.146 & 0.984 & 0.170 & 0.971 & 0.196 & 0.961 \\
$A_{4}$ & 0.176 & 1.000 & 0.246 & 1.000 & 0.322 & 1.000 \\
$A_{5}$ & 0.174 & 0.993 & 0.253 & 0.984 & 0.335 & 0.966 \\
$A_{6}$ & 0.168 & 1.000 & 0.231 & 1.000 & 0.317 & 1.000
\end{tabular}

Panel d

$n(\max )=3$ for Sample Size $=250$

\begin{tabular}{ccccc}
\multicolumn{5}{c}{$n(\max )=3$ for Sample Size $=250$} \\
\hline GC & $n^{*}=0$ & $n^{*}=1$ & $n^{*}=2$ & $n^{*}=3$ \\
0.108 & 0.832 & 0.020 & 0.031 & 0.117 \\
1.000 & 0.731 & 0.028 & 0.055 & 0.186 \\
0.978 & 0.716 & 0.029 & 0.049 & 0.205 \\
1.000 & 0.609 & 0.038 & 0.081 & 0.272 \\
0.982 & 0.620 & 0.043 & 0.087 & 0.250 \\
1.000 & 0.621 & 0.045 & 0.083 & 0.251
\end{tabular}

Panel b: Sample Size $=500$

\begin{tabular}{ccccccc} 
& \multicolumn{2}{c}{$n=1$} & \multicolumn{2}{c}{$n=2$} & \multicolumn{2}{c}{$n=3$} \\
\cline { 2 - 7 } Parameters & $\mathrm{F}(1)$ & $\mathrm{GC}(1)$ & $\mathrm{F}(2)$ & $\mathrm{GC}(2)$ & $\mathrm{F}(3)$ & $\mathrm{GC}(3)$ \\
$A_{1}$ & 0.107 & 0.092 & 0.106 & 0.104 & 0.110 & 0.099 \\
$A_{2}$ & 0.123 & 1.000 & 0.138 & 1.000 & 0.168 & 1.000 \\
$A_{3}$ & 0.125 & 1.000 & 0.144 & 1.000 & 0.152 & 1.000 \\
$A_{4}$ & 0.137 & 1.000 & 0.158 & 1.000 & 0.179 & 1.000 \\
$A_{5}$ & 0.138 & 1.000 & 0.177 & 1.000 & 0.225 & 1.000 \\
$A_{6}$ & 0.142 & 1.000 & 0.178 & 1.000 & 0.202 & 1.000
\end{tabular}

Panel e $n(\max )=3$ for Sample Size $=500$

\begin{tabular}{ccccc}
\multicolumn{5}{c}{$n(\max )=3$ for Sample Size $=500$} \\
\hline GC & $n^{*}=0$ & $n^{*}=1$ & $n^{*}=2$ & $n^{*}=3$ \\
0.100 & 0.843 & 0.020 & 0.031 & 0.106 \\
1.000 & 0.797 & 0.026 & 0.039 & 0.138 \\
1.000 & 0.780 & 0.028 & 0.043 & 0.149 \\
1.000 & 0.732 & 0.035 & 0.050 & 0.183 \\
1.000 & 0.723 & 0.030 & 0.059 & 0.188 \\
1.000 & 0.748 & 0.029 & 0.047 & 0.176
\end{tabular}

Panel c: Sample Size $=1000$

\begin{tabular}{ccccccc} 
& \multicolumn{2}{c}{$n=1$} & \multicolumn{2}{c}{$n=2$} & \multicolumn{2}{c}{$n=3$} \\
\cline { 2 - 7 } Parameters & $\mathrm{F}(1)$ & $\mathrm{GC}(1)$ & $\mathrm{F}(2)$ & $\mathrm{GC}(2)$ & $\mathrm{F}(3)$ & $\mathrm{GC}(3)$ \\
$A_{1}$ & 0.095 & 0.109 & 0.108 & 0.108 & 0.107 & 0.105 \\
$A_{2}$ & 0.112 & 1.000 & 0.106 & 1.000 & 0.134 & 1.000 \\
$A_{3}$ & 0.098 & 1.000 & 0.118 & 1.000 & 0.120 & 1.000 \\
$A_{4}$ & 0.128 & 1.000 & 0.144 & 1.000 & 0.155 & 1.000 \\
$A_{5}$ & 0.116 & 1.000 & 0.146 & 1.000 & 0.162 & 1.000 \\
$A_{6}$ & 0.118 & 1.000 & 0.129 & 1.000 & 0.156 & 1.000
\end{tabular}

Panel $\mathrm{f}$

\begin{tabular}{ccccc}
\multicolumn{5}{c}{$n(\max )=3$ for Sample Size $=1000$} \\
\hline GC & $n^{*}=0$ & $n^{*}=1$ & $n^{*}=2$ & $n^{*}=3$ \\
0.108 & 0.851 & 0.019 & 0.026 & 0.103 \\
1.000 & 0.828 & 0.024 & 0.031 & 0.117 \\
1.000 & 0.821 & 0.023 & 0.030 & 0.125 \\
1.000 & 0.790 & 0.024 & 0.046 & 0.140 \\
1.000 & 0.793 & 0.028 & 0.045 & 0.134 \\
1.000 & 0.784 & 0.031 & 0.040 & 0.145
\end{tabular}

Parameter sets:

Set $1=\|0.0,0.0\|$, Set $2=\|0.5,0.3\|$, Set $3=\|0.6,0.2\|$, Set $4=\|0.6,0.3\|$ Set $5=\|0.7,0.2\|$, Set $6=\| 0.6$, $-0.3 \|$ 
Table 3: Simulations With Sharp Breaks

INNOVATIVE OUTLIERS

Panel a: Sample Size $=250$

\begin{tabular}{ccccccc} 
& \multicolumn{2}{c}{$n=1$} & \multicolumn{2}{c}{$n=2$} & \multicolumn{2}{c}{$n=3$} \\
\cline { 2 - 7 } Parameters & $\mathrm{F}(1)$ & $\mathrm{GC}(1)$ & $\mathrm{F}(2)$ & $\mathrm{GC}(2)$ & $\mathrm{F}(3)$ & $\mathrm{GC}(3)$ \\
$A_{7}$ & 0.862 & 0.107 & 0.894 & 0.108 & 0.882 & 0.094 \\
$A_{8}$ & 0.830 & 0.102 & 0.876 & 0.125 & 0.876 & 0.152 \\
$A_{9}$ & 0.806 & 0.108 & 0.852 & 0.124 & 0.861 & 0.124 \\
$A_{10}$ & 0.856 & 1.000 & 0.884 & 1.000 & 0.918 & 1.000 \\
$A_{11}$ & 0.551 & 1.000 & 0.745 & 1.000 & 0.786 & 1.000
\end{tabular}

Panel b: Sample Size $=500$

\begin{tabular}{ccccccc} 
& \multicolumn{2}{c}{$n=1$} & \multicolumn{2}{c}{$n=2$} & \multicolumn{2}{c}{$n=3$} \\
\cline { 2 - 7 } Parameters & $\mathrm{F}(1)$ & $\mathrm{GC}(1)$ & $\mathrm{F}(2)$ & $\mathrm{GC}(2)$ & $\mathrm{F}(3)$ & $\mathrm{GC}(3)$ \\
$A_{7}$ & 0.993 & 0.091 & 0.996 & 0.108 & 0.996 & 0.099 \\
$A_{8}$ & 0.988 & 0.108 & 0.995 & 0.113 & 0.993 & 0.141 \\
$A_{9}$ & 0.977 & 0.102 & 0.989 & 0.122 & 0.988 & 0.108 \\
$A_{10}$ & 0.994 & 1.000 & 0.994 & 1.000 & 0.990 & 1.000 \\
$A_{11}$ & 0.734 & 1.000 & 0.890 & 1.000 & 0.933 & 1.000
\end{tabular}

Panel c: Sample Size $=1000$

\begin{tabular}{ccccccc} 
& \multicolumn{2}{c}{$n=1$} & \multicolumn{2}{c}{$n=2$} & \multicolumn{2}{c}{$n=3$} \\
\cline { 2 - 7 } Parameters & $\mathrm{F}(1)$ & $\mathrm{GC}(1)$ & $\mathrm{F}(2)$ & $\mathrm{GC}(2)$ & $\mathrm{F}(3)$ & $\mathrm{GC}(3)$ \\
$A_{7}$ & 1.000 & 0.110 & 1.000 & 0.104 & 1.000 & 0.102 \\
$A_{8}$ & 1.000 & 0.126 & 1.000 & 0.139 & 1.000 & 0.120 \\
$A_{9}$ & 1.000 & 0.096 & 1.000 & 0.119 & 1.000 & 0.105 \\
$A_{10}$ & 1.000 & 1.000 & 1.000 & 1.000 & 1.000 & 1.000 \\
$A_{11}$ & 0.951 & 1.000 & 0.995 & 1.000 & 0.999 & 1.000
\end{tabular}

ADDITIVE OUTLIERS

\begin{tabular}{cccccc}
\hline \multicolumn{5}{c}{ Panel d: Sample Size $=250$} \\
\multicolumn{2}{c}{$n=1$} & \multicolumn{2}{c}{$n=2$} & \multicolumn{2}{c}{$n=3$} \\
\hline $\mathrm{F}(1)$ & $\mathrm{GC}(1)$ & $\mathrm{F}(2)$ & $\mathrm{GC}(2)$ & $\mathrm{F}(3)$ & $\mathrm{GC}(3)$ \\
0.862 & 0.107 & 0.894 & 0.108 & 0.882 & 0.094 \\
0.572 & 0.120 & 0.337 & 0.136 & 0.350 & 0.160 \\
0.316 & 0.116 & 0.356 & 0.123 & 0.362 & 0.122 \\
0.314 & 1.000 & 0.638 & 1.000 & 0.678 & 1.000 \\
0.211 & 1.000 & 0.309 & 1.000 & 0.422 & 1.000
\end{tabular}

Panel e: Sample Size $=500$

\begin{tabular}{cccccc}
\multicolumn{2}{c}{$n=1$} & \multicolumn{2}{c}{$n=2$} & \multicolumn{2}{c}{$n=3$} \\
\hline $\mathrm{F}(1)$ & $\mathrm{GC}(1)$ & $\mathrm{F}(2)$ & $\mathrm{GC}(2)$ & $\mathrm{F}(3)$ & $\mathrm{GC}(3)$ \\
0.993 & 0.091 & 0.996 & 0.108 & 0.996 & 0.099 \\
0.826 & 0.102 & 0.468 & 0.121 & 0.485 & 0.149 \\
0.468 & 0.102 & 0.490 & 0.107 & 0.462 & 0.100 \\
0.470 & 1.000 & 0.846 & 1.000 & 0.814 & 1.000 \\
0.249 & 1.000 & 0.326 & 1.000 & 0.442 & 1.000
\end{tabular}

Panel f: Sample Size $=1000$

\begin{tabular}{cccccc}
\multicolumn{2}{c}{$n=1$} & \multicolumn{2}{c}{$n=2$} & \multicolumn{2}{c}{$n=3$} \\
\hline $\mathrm{F}(1)$ & $\mathrm{GC}(1)$ & $\mathrm{F}(2)$ & $\mathrm{GC}(2)$ & $\mathrm{F}(3)$ & $\mathrm{GC}(3)$ \\
1.000 & 0.110 & 1.000 & 0.104 & 1.000 & 0.102 \\
0.977 & 0.109 & 0.726 & 0.130 & 0.717 & 0.131 \\
0.732 & 0.095 & 0.753 & 0.118 & 0.717 & 0.104 \\
0.721 & 1.000 & 0.988 & 1.000 & 0.974 & 1.000 \\
0.318 & 1.000 & 0.470 & 1.000 & 0.608 & 1.000
\end{tabular}


Table 4: Smooth Breaks

INNOVATIVE OUTLIERS

ADDITIVE OUTLIERS

\begin{tabular}{|c|c|c|c|c|c|c|c|c|c|c|c|c|c|c|}
\hline \multicolumn{8}{|c|}{ IIVINUVAIIVE UUILIERS } & \multicolumn{7}{|c|}{ ADDIIIVE UUILIEKS } \\
\hline \multicolumn{15}{|c|}{ Type 1: Temporary Break } \\
\hline Parameters & $\mathrm{GC}(0)$ & $F(1)$ & $\mathrm{GC}(1)$ & $F(2)$ & $\mathrm{GC}(2)$ & $F(3)$ & $\mathrm{GC}(3)$ & $\mathrm{GC}(0)$ & $F(1)$ & $\mathrm{GC}(1)$ & $F(2)$ & $\mathrm{GC}(2)$ & $F(3)$ & $\mathrm{GC}(3)$ \\
\hline$A_{7}$ & 0.686 & 1.000 & 0.137 & 1.000 & 0.136 & 1.000 & 0.119 & 0.686 & 1.000 & 0.137 & 1.000 & 0.136 & 1.000 & 0.119 \\
\hline$A_{8}$ & 0.438 & 0.989 & 0.084 & 1.000 & 0.178 & 1.000 & 0.155 & 0.308 & 0.995 & 0.116 & 1.000 & 0.127 & 0.999 & 0.132 \\
\hline$A_{9}$ & 0.751 & 0.945 & 0.039 & 1.000 & 0.131 & 1.000 & 0.135 & 0.085 & 1.000 & 0.220 & 1.000 & 0.205 & 1.000 & 0.221 \\
\hline$A_{10}$ & 1.000 & 1.000 & 0.998 & 1.000 & 1.000 & 1.000 & 0.999 & 0.998 & 0.799 & 0.992 & 0.992 & 0.996 & 0.988 & 0.996 \\
\hline$A_{11}$ & 0.429 & 0.999 & 0.998 & 1.000 & 1.000 & 1.000 & 1.000 & 0.735 & 1.000 & 0.998 & 1.000 & 0.999 & 1.000 & 0.997 \\
\hline \multicolumn{15}{|c|}{ Type 2: Change in Slope } \\
\hline Parameters & $\mathrm{GC}(0)$ & $F(1)$ & $\mathrm{GC}(1)$ & $F(2)$ & $\mathrm{GC}(2)$ & $F(3)$ & $\mathrm{GC}(3)$ & $\mathrm{GC}(0)$ & $F(1)$ & $\mathrm{GC}(1)$ & $F(2)$ & $\mathrm{GC}(2)$ & $F(3)$ & $\mathrm{GC}(3)$ \\
\hline$A_{7}$ & 0.850 & 1.000 & 0.102 & 1.000 & 0.105 & 1.000 & 0.097 & 0.850 & 1.000 & 0.102 & 1.000 & 0.105 & 1.000 & 0.097 \\
\hline$A_{8}$ & 0.856 & 0.999 & 0.117 & 0.998 & 0.117 & 0.997 & 0.125 & 0.286 & 0.747 & 0.119 & 0.657 & 0.117 & 0.620 & 0.117 \\
\hline$A_{9}$ & 0.549 & 1.000 & 0.118 & 0.999 & 0.123 & 0.998 & 0.146 & 0.347 & 0.696 & 0.124 & 0.618 & 0.131 & 0.616 & 0.148 \\
\hline$A_{10}$ & 1.000 & 1.000 & 1.000 & 1.000 & 1.000 & 0.999 & 1.000 & 0.987 & 0.968 & 1.000 & 0.975 & 1.000 & 0.970 & 0.999 \\
\hline$A_{11}$ & 1.000 & 1.000 & 1.000 & 1.000 & 1.000 & 0.999 & 1.000 & 1.000 & 0.270 & 1.000 & 0.476 & 1.000 & 0.580 & 0.999 \\
\hline \multicolumn{15}{|c|}{ Type 3: LSTAR Break at 2T/3 } \\
\hline Parameters & $\mathrm{GC}(0)$ & $F(1)$ & $\mathrm{GC}(1)$ & $F(2)$ & $\mathrm{GC}(2)$ & $F(3)$ & $\mathrm{GC}(3)$ & $\mathrm{GC}(0)$ & $F(1)$ & $\mathrm{GC}(1)$ & $F(2)$ & $\mathrm{GC}(2)$ & $F(3)$ & $\mathrm{GC}(3)$ \\
\hline$A_{7}$ & 0.819 & 1.000 & 0.114 & 1.000 & 0.109 & 1.000 & 0.106 & 0.819 & 1.000 & 0.114 & 1.000 & 0.109 & 1.000 & 0.106 \\
\hline$A_{8}$ & 0.765 & 1.000 & 0.149 & 1.000 & 0.141 & 1.000 & 0.120 & 0.280 & 0.854 & 0.110 & 0.877 & 0.117 & 0.853 & 0.117 \\
\hline$A_{9}$ & 0.192 & 1.000 & 0.105 & 1.000 & 0.117 & 1.000 & 0.136 & 0.395 & 0.814 & 0.135 & 0.837 & 0.124 & 0.821 & 0.151 \\
\hline$A_{10}$ & 1.000 & 1.000 & 1.000 & 1.000 & 1.000 & 1.000 & 1.000 & 0.985 & 0.975 & 1.000 & 0.991 & 1.000 & 0.987 & 0.999 \\
\hline$A_{11}$ & 1.000 & 0.999 & 1.000 & 1.000 & 1.000 & 1.000 & 1.000 & 1.000 & 0.563 & 1.000 & 0.669 & 1.000 & 0.792 & 0.999 \\
\hline
\end{tabular}

\section{Continued on Next Page}


Type 4: ESTAR Break at 2T/3

\begin{tabular}{|c|c|c|c|c|c|c|c|c|c|c|c|c|c|c|}
\hline Parameters & $\mathrm{GC}(0)$ & $F(1)$ & $\mathrm{GC}(1)$ & $F(2)$ & $\mathrm{GC}(2)$ & $F(3)$ & $\mathrm{GC}(3)$ & $\mathrm{GC}(0)$ & $F(1)$ & $\mathrm{GC}(1)$ & $F(2)$ & $\mathrm{GC}(2)$ & $F(3)$ & $\mathrm{GC}(3)$ \\
\hline$A_{7}$ & 0.419 & 1.000 & 0.381 & 1.000 & 0.104 & 1.000 & 0.099 & 0.419 & 1.000 & 0.381 & 1.000 & 0.104 & 1.000 & 0.099 \\
\hline$A_{8}$ & 0.230 & 1.000 & 0.594 & 1.000 & 0.115 & 1.000 & 0.129 & 0.190 & 0.994 & 0.148 & 0.998 & 0.119 & 0.998 & 0.116 \\
\hline$A_{9}$ & 0.778 & 1.000 & 0.285 & 1.000 & 0.119 & 1.000 & 0.127 & 0.077 & 0.996 & 0.236 & 0.998 & 0.136 & 0.997 & 0.160 \\
\hline$A_{10}$ & 1.000 & 1.000 & 1.000 & 1.000 & 1.000 & 1.000 & 1.000 & 0.998 & 0.767 & 0.998 & 0.987 & 0.999 & 0.990 & 0.999 \\
\hline$A_{11}$ & 0.998 & 1.000 & 1.000 & 1.000 & 1.000 & 1.000 & 1.000 & 0.956 & 0.999 & 1.000 & 0.999 & 1.000 & 0.998 & 0.999 \\
\hline & & \multicolumn{13}{|c|}{ Type 5: Offsetting LSTAR Breaks at T/5 and 3T/4 } \\
\hline Parameters & $\mathrm{GC}(0)$ & $F(1)$ & $\mathrm{GC}(1)$ & $F(2)$ & $\mathrm{GC}(2)$ & $F(3)$ & $\mathrm{GC}(3)$ & $\mathrm{GC}(0)$ & $F(1)$ & $\mathrm{GC}(1)$ & $F(2)$ & $\mathrm{GC}(2)$ & $F(3)$ & $\mathrm{GC}(3)$ \\
\hline$A_{7}$ & 0.819 & 1.000 & 0.213 & 1.000 & 0.119 & 1.000 & 0.105 & 0.819 & 1.000 & 0.213 & 1.000 & 0.119 & 1.000 & 0.105 \\
\hline$A_{8}$ & 0.212 & 1.000 & 0.325 & 1.000 & 0.144 & 1.000 & 0.132 & 0.319 & 0.998 & 0.124 & 0.996 & 0.111 & 0.994 & 0.125 \\
\hline$A_{9}$ & 0.622 & 1.000 & 0.229 & 1.000 & 0.117 & 1.000 & 0.148 & 0.124 & 1.000 & 0.168 & 0.999 & 0.158 & 0.998 & 0.164 \\
\hline$A_{10}$ & 0.992 & 1.000 & 1.000 & 1.000 & 1.000 & 1.000 & 1.000 & 1.000 & 0.877 & 0.999 & 0.950 & 0.999 & 0.962 & 0.999 \\
\hline$A_{11}$ & 1.000 & 1.000 & 1.000 & 1.000 & 1.000 & 1.000 & 1.000 & 0.930 & 0.999 & 1.000 & 0.999 & 1.000 & 0.999 & 0.999 \\
\hline & \multicolumn{14}{|c|}{ Type 6: ESTAR Breaks at T/5 and 3T/4 } \\
\hline Parameters & $\mathrm{GC}(0)$ & $F(1)$ & $\mathrm{GC}(1)$ & $F(2)$ & $\mathrm{GC}(2)$ & $F(3)$ & $\mathrm{GC}(3)$ & $\mathrm{GC}(0)$ & $F(1)$ & $\mathrm{GC}(1)$ & $F(2)$ & $\mathrm{GC}(2)$ & $F(3)$ & $\mathrm{GC}(3)$ \\
\hline$A_{7}$ & 0.641 & 1.000 & 0.201 & 1.000 & 0.124 & 1.000 & 0.105 & 0.641 & 1.000 & 0.201 & 1.000 & 0.124 & 1.000 & 0.105 \\
\hline$A_{8}$ & 0.698 & 1.000 & 0.231 & 1.000 & 0.133 & 1.000 & 0.154 & 0.199 & 0.843 & 0.122 & 0.826 & 0.117 & 0.875 & 0.123 \\
\hline$A_{9}$ & 0.218 & 1.000 & 0.136 & 1.000 & 0.115 & 1.000 & 0.123 & 0.322 & 0.783 & 0.168 & 0.800 & 0.167 & 0.851 & 0.143 \\
\hline$A_{10}$ & 1.000 & 1.000 & 1.000 & 1.000 & 1.000 & 1.000 & 1.000 & 0.990 & 0.965 & 0.998 & 0.982 & 0.999 & 0.990 & 0.999 \\
\hline$A_{11}$ & 1.000 & 0.898 & 1.000 & 0.979 & 1.000 & 1.000 & 1.000 & 0.999 & 0.670 & 1.000 & 0.744 & 1.000 & 0.809 & 0.999 \\
\hline \multicolumn{15}{|c|}{ Type 7: Trigonometric Break } \\
\hline Parameters & $\mathrm{GC}(0)$ & $F(1)$ & $\mathrm{GC}(1)$ & $F(2)$ & $\mathrm{GC}(2)$ & $F(3)$ & $\mathrm{GC}(3)$ & $\mathrm{GC}(0)$ & $F(1)$ & $\mathrm{GC}(1)$ & $F(2)$ & $\mathrm{GC}(2)$ & $F(3)$ & $\mathrm{GC}(3)$ \\
\hline$A_{7}$ & 0.204 & 0.543 & 0.170 & 1.000 & 0.105 & 1.000 & 0.113 & 0.204 & 0.543 & 0.170 & 1.000 & 0.105 & 1.000 & 0.113 \\
\hline$A_{8}$ & 0.248 & 0.063 & 0.470 & 1.000 & 0.125 & 1.000 & 0.132 & 0.107 & 0.102 & 0.136 & 1.000 & 0.116 & 0.999 & 0.126 \\
\hline$A_{9}$ & 0.012 & 0.003 & 0.035 & 1.000 & 0.127 & 1.000 & 0.149 & 0.295 & 0.133 & 0.330 & 0.998 & 0.135 & 0.997 & 0.162 \\
\hline$A_{10}$ & 0.691 & 0.993 & 0.483 & 1.000 & 1.000 & 1.000 & 1.000 & 0.975 & 0.476 & 0.976 & 0.998 & 0.999 & 0.998 & 0.998 \\
\hline$A_{11}$ & 1.000 & 0.997 & 1.000 & 1.000 & 1.000 & 1.000 & 1.000 & 0.996 & 0.443 & 0.997 & 0.997 & 1.000 & 0.994 & 0.999 \\
\hline
\end{tabular}


Table 5: Correlated Shocks and Smooth Breaks

INNOVATIVE OUTLIERS

ADDITIVE OUTLIERS

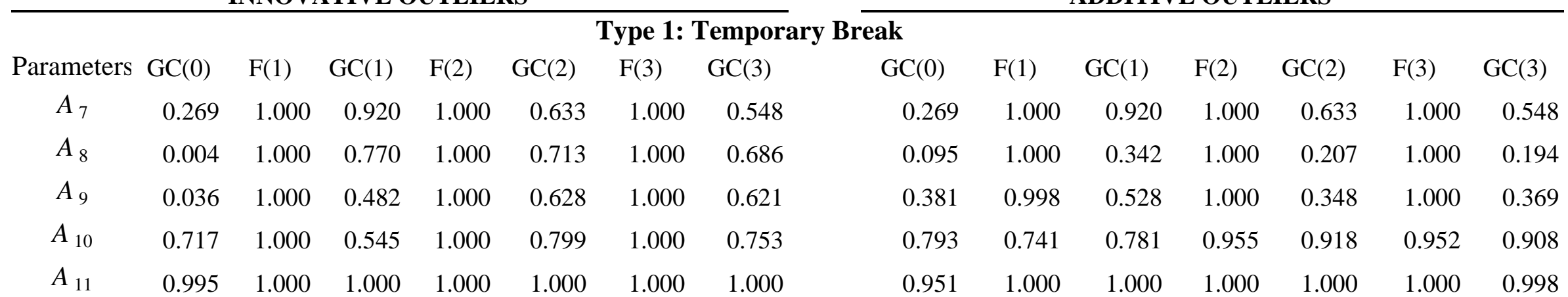

Type 2: Change in Slope

$\begin{array}{cccccccccccccccc}\text { Parameters } & \mathrm{GC}(0) & \mathrm{F}(1) & \mathrm{GC}(1) & \mathrm{F}(2) & \mathrm{GC}(2) & \mathrm{F}(3) & \mathrm{GC}(3) & \mathrm{GC}(0) & \mathrm{F}(1) & \mathrm{GC}(1) & \mathrm{F}(2) & \mathrm{GC}(2) & \mathrm{F}(3) & \mathrm{GC}(3) \\ A_{7} & 0.986 & 1.000 & 0.101 & 0.999 & 0.103 & 0.997 & 0.099 & 0.986 & 1.000 & 0.101 & 0.999 & 0.103 & 0.997 & 0.099 \\ A_{8} & 0.987 & 0.994 & 0.120 & 0.985 & 0.117 & 0.981 & 0.127 & 0.437 & 0.667 & 0.116 & 0.580 & 0.116 & 0.555 & 0.116 \\ A_{9} & 0.921 & 0.998 & 0.122 & 0.994 & 0.127 & 0.991 & 0.151 & 0.500 & 0.616 & 0.127 & 0.543 & 0.136 & 0.541 & 0.158 \\ A_{10} & 0.999 & 0.999 & 1.000 & 0.996 & 1.000 & 0.995 & 0.999 & 0.757 & 0.908 & 0.985 & 0.932 & 0.987 & 0.929 & 0.983 \\ A_{11} & 1.000 & 1.000 & 1.000 & 0.999 & 1.000 & 0.998 & 1.000 & 1.000 & 0.257 & 0.999 & 0.443 & 0.999 & 0.513 & 0.998\end{array}$

\section{Type 3: LSTAR Break at 2T/3}

$\begin{array}{cccccccccccccccc}\text { Parameters } & \mathrm{GC}(0) & \mathrm{F}(1) & \mathrm{GC}(1) & \mathrm{F}(2) & \mathrm{GC}(2) & \mathrm{F}(3) & \mathrm{GC}(3) & \mathrm{GC}(0) & \mathrm{F}(1) & \mathrm{GC}(1) & \mathrm{F}(2) & \mathrm{GC}(2) & \mathrm{F}(3) & \mathrm{GC}(3) \\ A_{7} & 0.998 & 1.000 & 0.200 & 1.000 & 0.107 & 1.000 & 0.109 & 0.998 & 1.000 & 0.200 & 1.000 & 0.107 & 1.000 & 0.109 \\ A_{8} & 0.991 & 0.985 & 0.323 & 0.999 & 0.131 & 0.999 & 0.128 & 0.544 & 0.754 & 0.122 & 0.794 & 0.117 & 0.771 & 0.118 \\ A_{9} & 0.780 & 0.999 & 0.221 & 1.000 & 0.112 & 1.000 & 0.154 & 0.640 & 0.693 & 0.166 & 0.746 & 0.128 & 0.740 & 0.163 \\ A_{10} & 0.995 & 0.988 & 1.000 & 1.000 & 1.000 & 1.000 & 0.999 & 0.686 & 0.891 & 0.969 & 0.960 & 0.988 & 0.951 & 0.980 \\ A_{11} & 1.000 & 0.997 & 1.000 & 0.998 & 1.000 & 0.999 & 1.000 & 1.000 & 0.572 & 1.000 & 0.664 & 0.999 & 0.770 & 0.998\end{array}$

\section{Continued on Next Page}




\section{Type 4: ESTAR Break at 2T/3}

\begin{tabular}{|c|c|c|c|c|c|c|c|c|c|c|c|c|c|c|}
\hline Parameters & $\mathrm{GC}(0)$ & $\mathrm{F}(1)$ & GC(1) & $F(2)$ & $\mathrm{GC}(2)$ & $F(3)$ & GC(3) & $\mathrm{GC}(0)$ & $\mathrm{F}(1)$ & GC(1) & $\mathrm{F}(2)$ & $\mathrm{GC}(2)$ & $\mathrm{F}(3)$ & GC(3) \\
\hline$A_{7}$ & 0.205 & 1.000 & 0.849 & 1.000 & 0.107 & 1.000 & 0.098 & 0.205 & 1.000 & 0.849 & 1.000 & 0.107 & 1.000 & 0.098 \\
\hline$A_{8}$ & 0.006 & 1.000 & 0.950 & 1.000 & 0.123 & 1.000 & 0.125 & 0.095 & 0.999 & 0.265 & 0.998 & 0.124 & 0.999 & 0.116 \\
\hline$A_{9}$ & 0.053 & 1.000 & 0.801 & 1.000 & 0.097 & 1.000 & 0.133 & 0.288 & 0.992 & 0.391 & 0.995 & 0.152 & 0.993 & 0.168 \\
\hline$A_{10}$ & 0.994 & 1.000 & 0.926 & 1.000 & 1.000 & 1.000 & 1.000 & 0.870 & 0.661 & 0.893 & 0.953 & 0.980 & 0.970 & 0.984 \\
\hline$A_{11}$ & 1.000 & 1.000 & 1.000 & 1.000 & 1.000 & 1.000 & 1.000 & 0.986 & 1.000 & 1.000 & 1.000 & 0.999 & 1.000 & 0.998 \\
\hline & & \multicolumn{13}{|c|}{ Type 5: Offsetting LSTAR Breaks at T/5 and 3T/4 } \\
\hline Parameters & $\mathrm{GC}(0)$ & $\mathrm{F}(1)$ & GC(1) & $\mathrm{F}(2)$ & GC(2) & $\mathrm{F}(3)$ & GC(3) & $\mathrm{GC}(0)$ & $\mathrm{F}(1)$ & GC(1) & $\mathrm{F}(2)$ & $\mathrm{GC}(2)$ & $\mathrm{F}(3)$ & GC(3) \\
\hline$A_{7}$ & 0.052 & 1.000 & 0.312 & 1.000 & 0.144 & 1.000 & 0.106 & 0.052 & 1.000 & 0.312 & 1.000 & 0.144 & 1.000 & 0.106 \\
\hline$A_{8}$ & 0.035 & 1.000 & 0.494 & 1.000 & 0.221 & 1.000 & 0.140 & 0.085 & 1.000 & 0.140 & 0.998 & 0.116 & 0.998 & 0.127 \\
\hline$A_{9}$ & 0.029 & 1.000 & 0.376 & 1.000 & 0.162 & 1.000 & 0.168 & 0.170 & 0.999 & 0.195 & 0.997 & 0.175 & 0.995 & 0.176 \\
\hline$A_{10}$ & 0.297 & 1.000 & 1.000 & 1.000 & 1.000 & 1.000 & 1.000 & 0.945 & 0.815 & 0.962 & 0.917 & 0.978 & 0.940 & 0.978 \\
\hline$A_{11}$ & 1.000 & 1.000 & 1.000 & 1.000 & 1.000 & 1.000 & 1.000 & 0.973 & 1.000 & 1.000 & 1.000 & 0.999 & 1.000 & 0.999 \\
\hline \multicolumn{15}{|c|}{ Type 6: ESTAR Breaks at T/5 and 3T/4 } \\
\hline Parameters & $\mathrm{GC}(0)$ & $\mathrm{F}(1)$ & GC(1) & $\mathrm{F}(2)$ & GC(2) & $\mathrm{F}(3)$ & GC(3) & $\mathrm{GC}(0)$ & $\mathrm{F}(1)$ & GC(1) & $\mathrm{F}(2)$ & $\mathrm{GC}(2)$ & $\mathrm{F}(3)$ & GC(3) \\
\hline$A_{7}$ & 0.988 & 1.000 & 0.458 & 1.000 & 0.213 & 1.000 & 0.104 & 0.988 & 1.000 & 0.458 & 1.000 & 0.213 & 1.000 & 0.104 \\
\hline$A_{8}$ & 0.992 & 0.991 & 0.567 & 0.995 & 0.298 & 1.000 & 0.146 & 0.444 & 0.762 & 0.155 & 0.751 & 0.129 & 0.815 & 0.121 \\
\hline$A_{9}$ & 0.857 & 0.998 & 0.391 & 0.999 & 0.230 & 1.000 & 0.125 & 0.576 & 0.688 & 0.230 & 0.715 & 0.203 & 0.774 & 0.152 \\
\hline$A_{10}$ & 0.892 & 0.999 & 0.998 & 1.000 & 0.998 & 1.000 & 1.000 & 0.693 & 0.853 & 0.953 & 0.915 & 0.969 & 0.966 & 0.985 \\
\hline$A_{11}$ & 1.000 & 0.800 & 1.000 & 0.961 & 1.000 & 1.000 & 1.000 & 1.000 & 0.703 & 1.000 & 0.752 & 1.000 & 0.799 & 0.998 \\
\hline \multicolumn{15}{|c|}{ Type 7: Trigonometric Break } \\
\hline arameters & $\mathrm{GC}(0)$ & $\mathrm{F}(1)$ & GC(1) & $\mathrm{F}(2)$ & $\mathrm{GC}(2)$ & $\mathrm{F}(3)$ & GC(3) & $\mathrm{GC}(0)$ & $\mathrm{F}(1)$ & GC(1) & $F(2)$ & GC(2) & $F(3)$ & GC(3) \\
\hline$A_{7}$ & 0.991 & 0.679 & 0.992 & 1.000 & 0.102 & 1.000 & 0.112 & 0.991 & 0.679 & 0.992 & 1.000 & 0.102 & 1.000 & 0.112 \\
\hline$A_{8}$ & 0.985 & 0.720 & 0.998 & 1.000 & 0.126 & 1.000 & 0.132 & 0.571 & 0.137 & 0.599 & 0.997 & 0.118 & 0.996 & 0.129 \\
\hline$A_{9}$ & 0.606 & 0.117 & 0.796 & 1.000 & 0.131 & 1.000 & 0.161 & 0.799 & 0.199 & 0.831 & 0.991 & 0.138 & 0.984 & 0.171 \\
\hline$A_{10}$ & 0.012 & 0.997 & 0.088 & 1.000 & 1.000 & 1.000 & 1.000 & 0.477 & 0.249 & 0.523 & 0.991 & 0.982 & 0.990 & 0.983 \\
\hline$A_{11}$ & 1.000 & 1.000 & 1.000 & 1.000 & 1.000 & 1.000 & 1.000 & 1.000 & 0.614 & 0.999 & 0.999 & 1.000 & 0.999 & 0.999 \\
\hline
\end{tabular}


Table 6: Bai-Perron Test and Smooth Breaks

Type 1: Temporary Break

$\begin{array}{ccccccc}\text { Parameters } & \text { GC } & \mathrm{B}(0) & \mathrm{B}(1) & \mathrm{B}(2) & \mathrm{B}(3) & \mathrm{B}(4) \\ A_{7} & 0.136 & 0.000 & 0.000 & 0.463 & 0.305 & 0.232 \\ A_{8} & 0.105 & 0.000 & 0.000 & 0.001 & 0.017 & 0.982 \\ A_{9} & 0.156 & 0.000 & 0.000 & 0.000 & 0.015 & 0.985 \\ A_{10} & 0.209 & 0.000 & 0.000 & 0.000 & 0.000 & 1.000 \\ A_{11} & 0.988 & 0.000 & 0.000 & 0.000 & 0.000 & 1.000 \\ & \text { Type 2: Change in Slope } & & & \\ \text { Parameters } & \text { GC } & \mathrm{B}(0) & \mathrm{B}(1) & \mathrm{B}(2) & \mathrm{B}(3) & \mathrm{B}(4) \\ A_{7} & 0.384 & 0.679 & 0.206 & 0.087 & 0.025 & 0.003 \\ A_{8} & 0.153 & 0.000 & 0.000 & 0.000 & 0.027 & 0.973 \\ A_{9} & 0.405 & 0.000 & 0.000 & 0.001 & 0.016 & 0.983 \\ A_{10} & 0.797 & 0.000 & 0.000 & 0.000 & 0.000 & 1.000 \\ A_{11} & 0.993 & 0.000 & 0.000 & 0.000 & 0.000 & 1.000\end{array}$

Type 3: LSTAR Break at 2T/3

$\begin{array}{ccccccc}\text { Parameters } & \mathrm{GC} & \mathrm{B}(0) & \mathrm{B}(1) & \mathrm{B}(2) & \mathrm{B}(3) & \mathrm{B}(4) \\ A_{7} & 0.157 & 0.063 & 0.265 & 0.519 & 0.119 & 0.034 \\ A_{8} & 0.148 & 0.000 & 0.000 & 0.000 & 0.009 & 0.991 \\ A_{9} & 0.367 & 0.000 & 0.000 & 0.001 & 0.005 & 0.994 \\ A_{10} & 0.813 & 0.000 & 0.000 & 0.000 & 0.000 & 1.000 \\ A_{11} & 0.972 & 0.000 & 0.000 & 0.000 & 0.000 & 1.000\end{array}$

Type 4: ESTAR Break at 2T/3

$\begin{array}{ccccccc}\text { Parameters } & \mathrm{GC} & \mathrm{B}(0) & \mathrm{B}(1) & \mathrm{B}(2) & \mathrm{B}(3) & \mathrm{B}(4) \\ A_{7} & 0.152 & 0.000 & 0.000 & 0.001 & 0.034 & 0.965 \\ A_{8} & 0.098 & 0.000 & 0.000 & 0.000 & 0.000 & 1.000 \\ A_{9} & 0.141 & 0.000 & 0.000 & 0.000 & 0.000 & 1.000 \\ A_{10} & 0.699 & 0.000 & 0.000 & 0.000 & 0.000 & 1.000 \\ A_{11} & 0.985 & 0.000 & 0.000 & 0.000 & 0.002 & 0.998\end{array}$

Type 5: Offsetting LSTAR Breaks at T/5 and 3T/4

$\begin{array}{lllllll}\text { Parameters } & \text { GC } & \mathrm{B}(0) & \mathrm{B}(1) & \mathrm{B}(2) & \mathrm{B}(3) & \mathrm{B}(4)\end{array}$

$\begin{array}{lllllll}A_{7} & 0.163 & 0.000 & 0.000 & 0.008 & 0.307 & 0.685\end{array}$

$\begin{array}{lllllll}A_{8} & 0.216 & 0.000 & 0.000 & 0.000 & 0.001 & 0.999\end{array}$

$\begin{array}{llllllll}A_{9} & 0.299 & 0.000 & 0.000 & 0.000 & 0.001 & 0.999\end{array}$

$\begin{array}{lllllll}A_{10} & 0.440 & 0.000 & 0.000 & 0.000 & 0.000 & 1.000\end{array}$

$\begin{array}{lllllll}A_{11} & 0.972 & 0.000 & 0.000 & 0.000 & 0.000 & 1.000\end{array}$

Type 6: ESTAR Breaks at $T / 5$ and $3 T / 4$

$\begin{array}{cllllll}\text { Parameters } & \mathrm{GC} & \mathrm{B}(0) & \mathrm{B}(1) & \mathrm{B}(2) & \mathrm{B}(3) & \mathrm{B}(4) \\ A_{7} & 0.214 & 0.000 & 0.000 & 0.000 & 0.005 & 0.995 \\ A_{8} & 0.332 & 0.000 & 0.000 & 0.000 & 0.000 & 1.000 \\ A_{9} & 0.534 & 0.000 & 0.000 & 0.000 & 0.000 & 1.000 \\ A_{10} & 0.369 & 0.000 & 0.000 & 0.000 & 0.000 & 1.000 \\ A_{11} & 0.856 & 0.000 & 0.000 & 0.000 & 0.000 & 1.000\end{array}$

Type 7: Trigonometric Break

$\begin{array}{ccccccc}\text { Parameters } & \text { GC } & \mathrm{B}(0) & \mathrm{B}(1) & \mathrm{B}(2) & \mathrm{B}(3) & \mathrm{B}(4) \\ A_{7} & 0.394 & 0.000 & 0.000 & 0.000 & 0.000 & 1.000 \\ A_{8} & 0.485 & 0.000 & 0.000 & 0.000 & 0.000 & 1.000 \\ A_{9} & 0.519 & 0.000 & 0.000 & 0.000 & 0.000 & 1.000 \\ A_{10} & 0.275 & 0.000 & 0.000 & 0.000 & 0.000 & 1.000 \\ A_{11} & 0.475 & 0.000 & 0.000 & 0.000 & 0.000 & 1.000\end{array}$



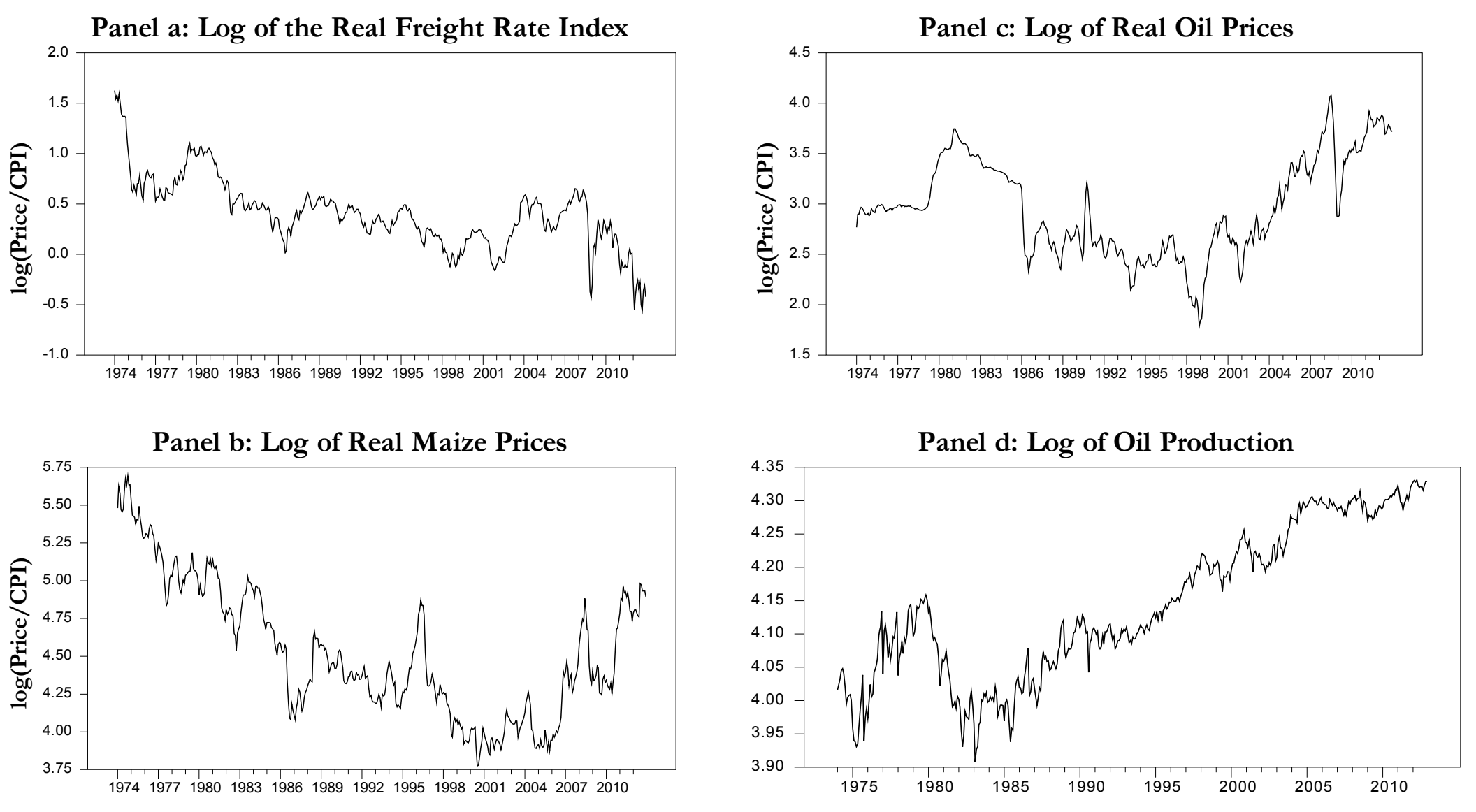

Figure 1: The Four Variables Used in the Model 


\section{Sharp Breaks}

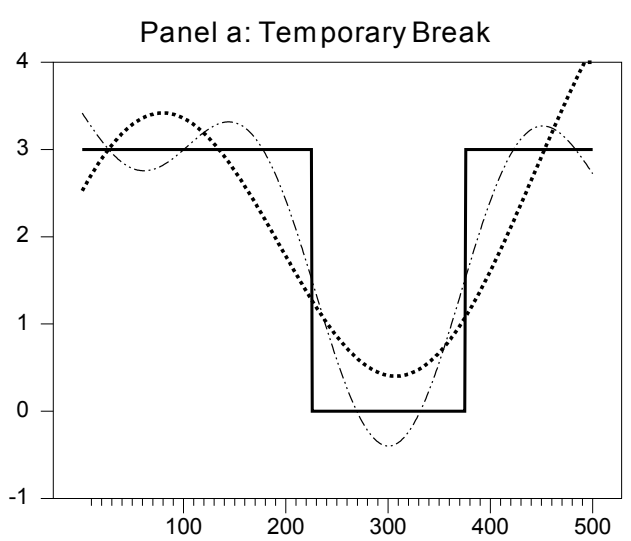

100

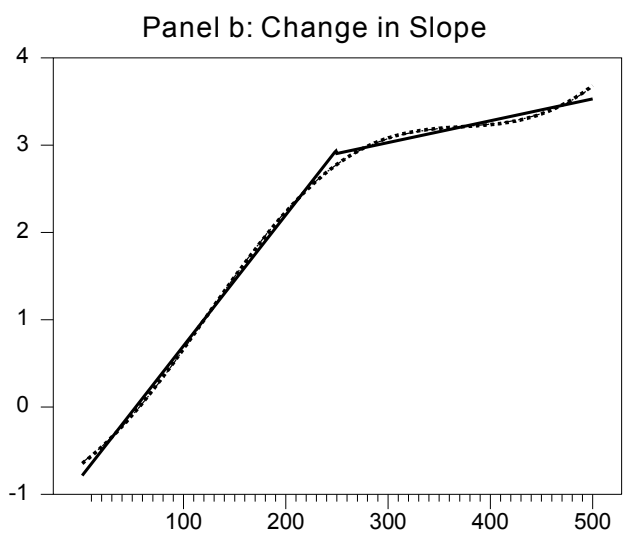

Series:
One Break

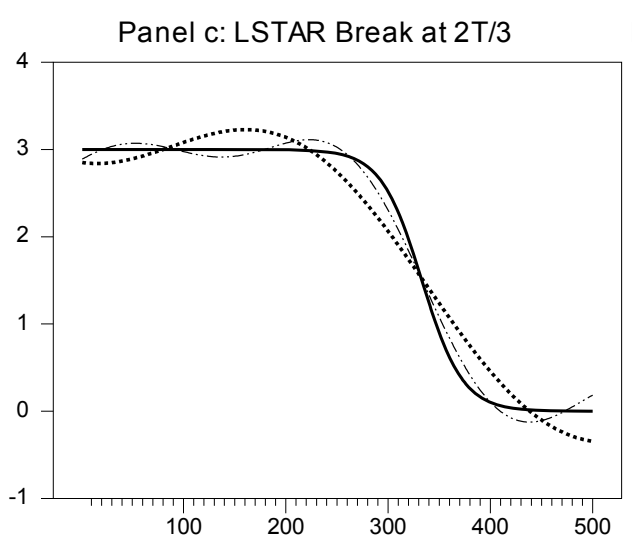

100

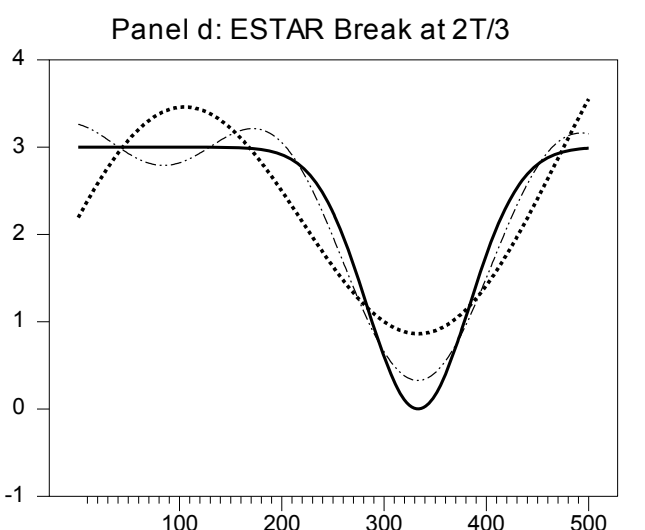

1-Frequency:__- 2-Frequencies:
Two Breaks

Panel e: Offs etting LSTAR Breaks at T/5 and 3T/4

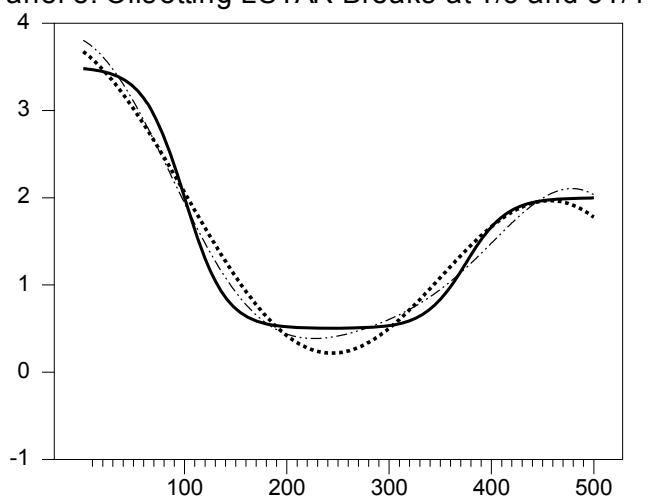

Panel f: ESTAR Breaks at T/5 and 3T/4

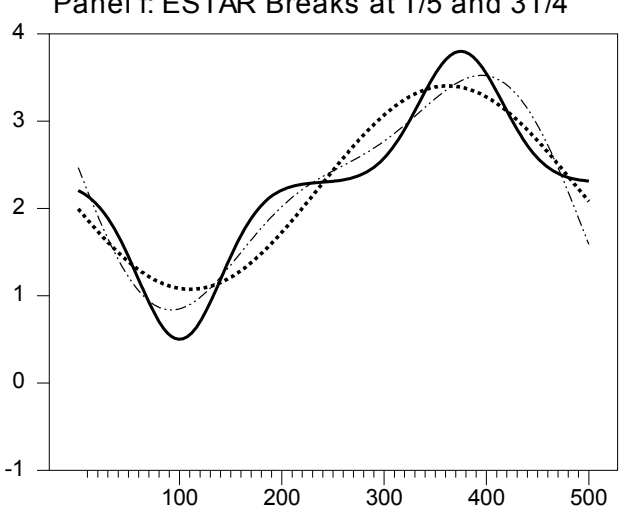

Figure 2: Sharp, LSTAR and ESTAR Breaks 

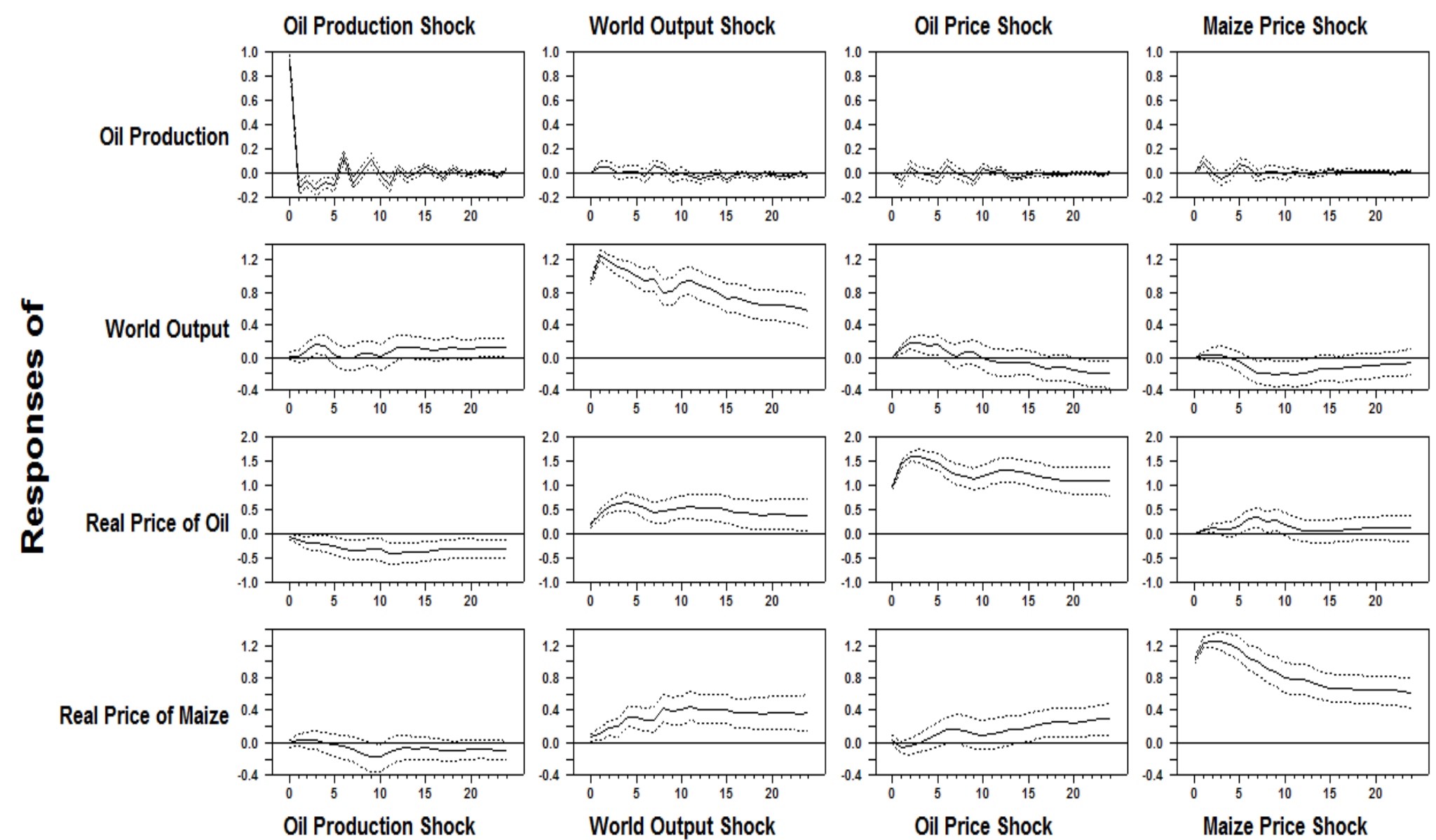

Figure 3: Impulse Responses from a Linear VAR 

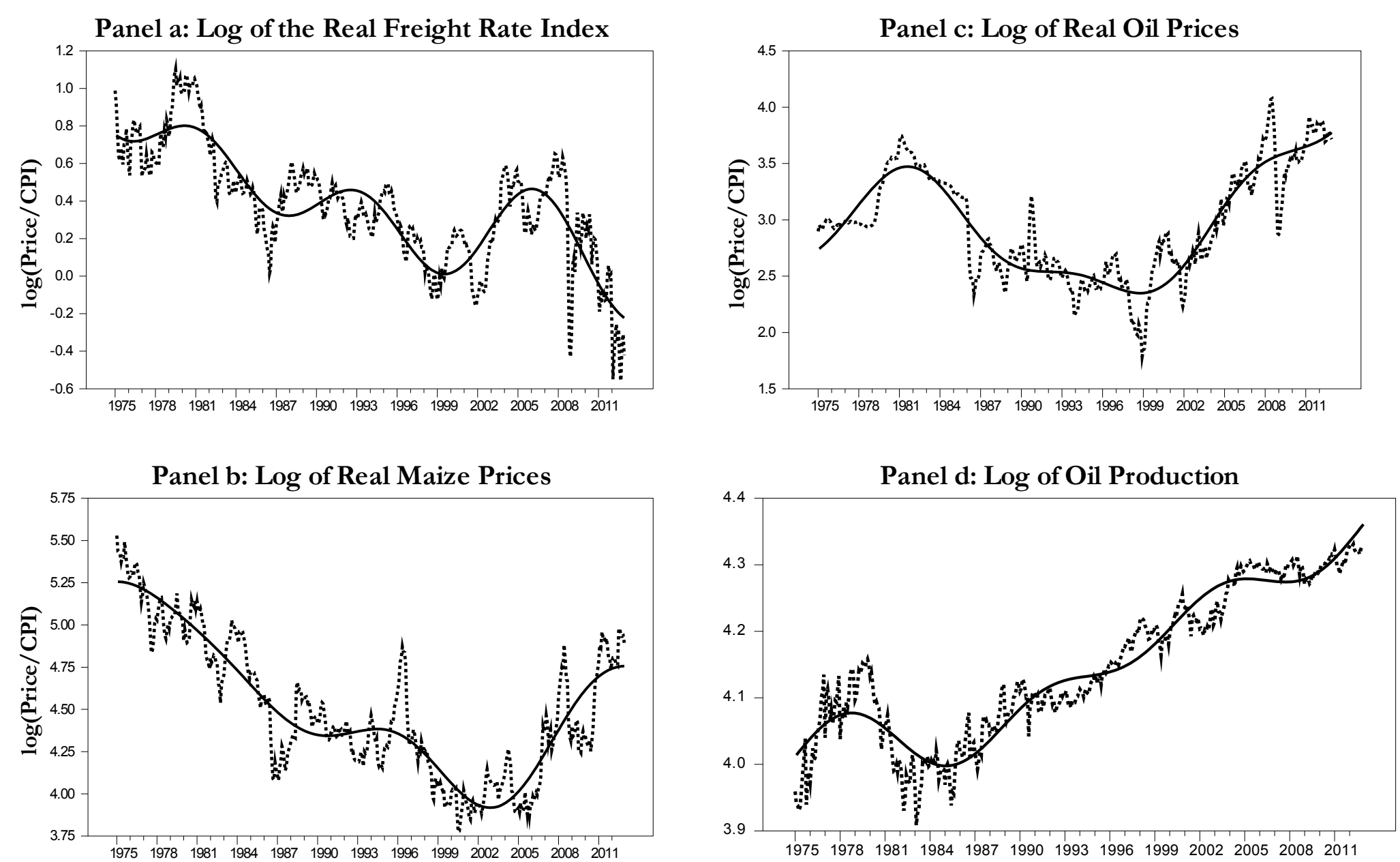

Figure 4: Actual Values and Fitted Means Using Three Frequencies 

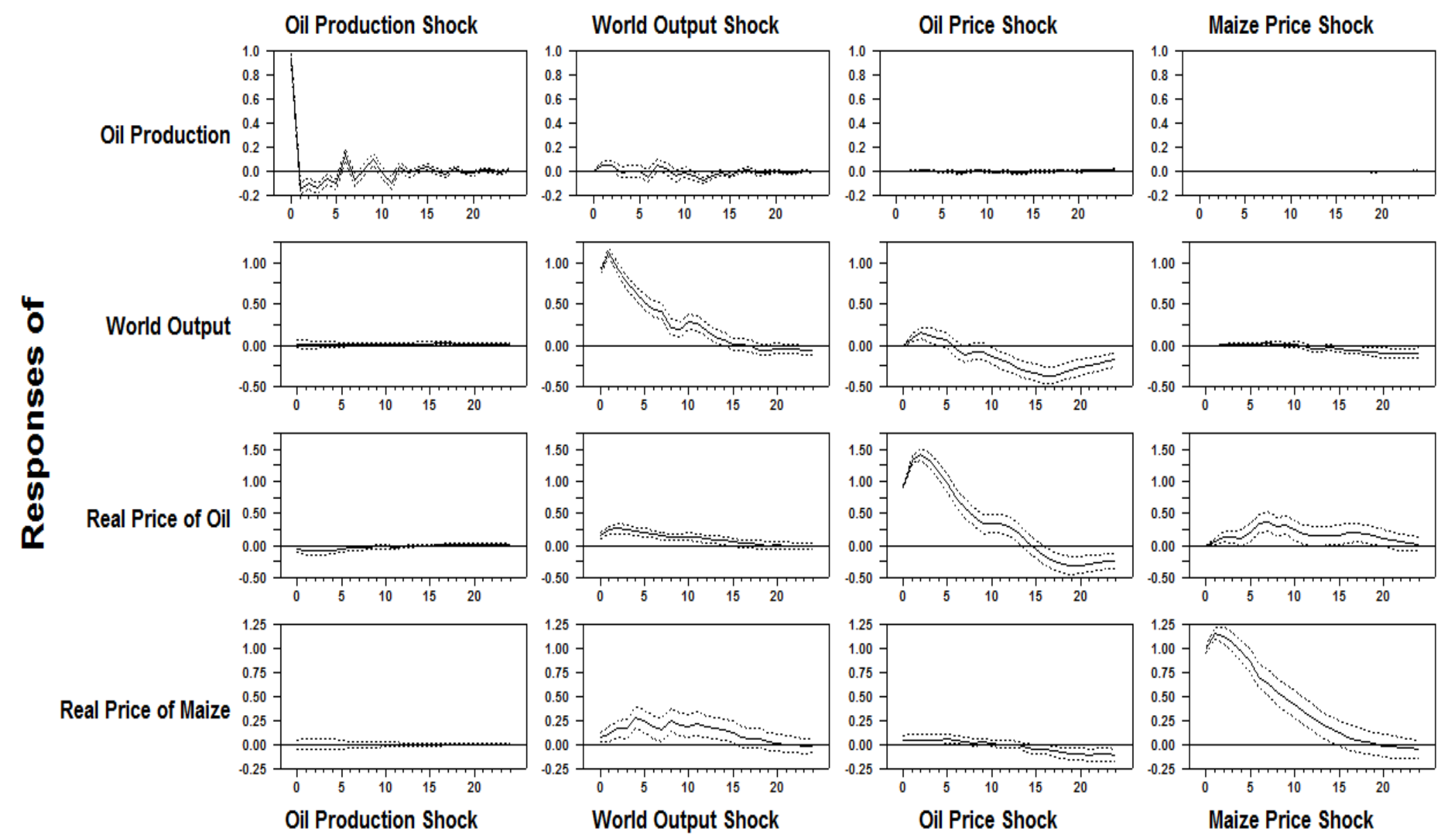

Figure 5: Impulse Responses using the Fourier Frequencies 